\title{
Uso agrícola e florestal do biochar: estado da arte e futuras pesquisas
}

\author{
Agricultural and forestry use of biochar: state of the art and future research \\ Uso agrícola y forestal del biocarbón: estado del arte y investigación futura
}

Cezar Dias Cardoso Júnior

ORCID: https://orcid.org/0000-0002-2472-0331 Universidade Federal Rural do Rio de Janeiro, Brasil

E-mail: cezar.cardosojr@gmail.com

Alexandre Santos Pimenta

ORCID: https://orcid.org/0000-0002-2134-2080 Universidade Federal do Rio Grande do Norte, Brasil

E-mail: alexandre.pimenta@ufrn.br

Elias Costa de Souza

ORCID: https://orcid.org/0000-0001-9514-635X

Universidade de São Paulo, Brasil

E-mail: eliasrem@hotmail.com

Allana Katiussya Silva Pereira

ORCID: https://orcid.org/0000-0003-0425-4668

Universidade de São Paulo, Brasil

E-mail: allana.florestal@gmail.com

Ananias Francisco Dias Júnior

ORCID: https://orcid.org/0000-0001-9974-0567

Universidade Federal do Espírito Santo, Brasil

E-mail: ananias.dias@ufes.br

\begin{abstract}
Resumo
Objetivo: O biochar é um dos principais produtos gerados a partir da pirólise da biomassa. Entre as diversas aplicações possíveis, uma que vem sendo estudada ao longo dos últimos anos é o uso desse material no solo, com o objetivo de melhorar as propriedades em sítios de plantios agrícolas e florestais. Metodologia: assim, este trabalho tem como objetivo verificar o estado da arte das pesquisas referentes ao biochar e sua aplicação, identificando as principais interações que ocorrem entre o biochar e o solo, bem como com os elementos que o compõem. Resultados e discussão: Após a revisão de literatura e a discussão dos principais aspectos do uso do biochar, foi identificado que os dois tópicos que merecem maior atenção devido à ausência de trabalhos suficientes para aprimorar as discussões estão relacionados às máquinas e implementos agrícolas utilizados para a aplicação do biochar no solo e à análise da viabilidade econômica da utilização desse produto em plantios. Conclusão: Com a realização de mais trabalhos abordando esses dois tópicos, será possível avançar e aprimorar os aspectos práticos da aplicação do biochar, difundindo esta técnica que pode contribuir de maneira significativa para o avanço da silvicultura no Brasil e no mundo.
\end{abstract}

Palavras-chave: Biocarvão; Biomassa; Culturas agrícolas; Silvicultura; Solo.

\begin{abstract}
Objective: Biochar is one of the products generated from biomass pyrolysis. Among the various possible applications, one that has been studied over the last few years is the employment of this material as a soil conditioner, aiming to improve properties in agricultural and forestry plantations. Methodology: Thus, this work aims to verify the state of the art of research related to biochar and its application, identifying the main interactions that occur between biochar and the soil, as well as with the elements that compose it. Results and discussion: After reviewing the literature and discussing the main aspects of the use of biochar, it was identified that the two topics that deserve greater attention due to the lack of sufficient work to improve the discussions are related to agricultural machines and implements used for the application of biochar in the soil and the analysis of the economic viability of using this product in plantations. Conclusion: With more work on these two topics, it will be possible to advance and improve the practical aspects of the application of biochar, disseminating this technique that can significantly contribute to the advancement of forestry in Brazil and worldwide.
\end{abstract}

Keywords: Biochar; Biomass; Agricultural crops; Forestry; Soil.

\section{Resumen}

Objetivo: El biocarbón es uno de los principales productos generados a partir del pirólisis de biomasa. Entre las diversas aplicaciones posibles, una que se ha estudiado en los últimos años es la utilización de este material en el suelo, con el objetivo de mejorar las propiedades en plantaciones agrícolas y forestales. Metodología: Así, este trabajo tiene como 
objetivo verificar el estado del arte de la investigación relacionada con el biocarbón y su aplicación, identificando las principales interacciones que ocurren entre el biocarbón y el suelo, así como con los elementos que lo componen. Resultados y discusión: Luego de revisar la literatura y discutir los principales aspectos del uso del biocarbón, se identificó que los dos temas que merecen mayor atención debido a la falta de trabajo suficiente para mejorar las discusiones están relacionados con las máquinas agrícolas e implementos utilizados para la aplicación del biocarbón en el suelo y el análisis de la viabilidad económica del uso de este producto en plantaciones. Conclusión: Con más trabajo que aborde estos dos temas, será posible avanzar y mejorar los aspectos prácticos de la aplicación del biocarbón, difundiendo esta técnica que puede contribuir significativamente al avance de la silvicultura en Brasil y en todo el mundo.

Palabras clave: Biocarbón; Biomasa; Cultivos agrícolas; Silvicultura; Suelo.

\section{Introdução}

O biochar (ou biocarvão) é um material originário de vegetais, animais, carvão vegetal ou mineral rico em carbono orgânico, resistente à degradação química-biológica e pode ser observado em biomassa de microrganismos (Batista, 2018). Consiste em um dos produtos do processo de pirólise, cuja produção é dada através da degradação térmica de uma determinada biomassa em ambiente com concentrações deficientes (ou ausentes) de oxigênio e com temperaturas entre 300 e $900{ }^{\circ} \mathrm{C}$ (Batista, 2018).

De acordo com Guimarães (2017), o biochar tem estrutura periférica que proporciona a sua reatividade com material orgânico do ambiente e sua estrutura interna garante capacidade de preservação do carbono por milhares de anos. No processo de queima de biomassa podem ser utilizados os resíduos:

- $\quad$ Orgânicos urbanos como podas de árvores e lodo de esgoto;

- Agrícolas como sobras de culturas, bagaço e palha oriunda da cana-de-açúcar;

- Industriais com as oriundas da indústria de papel e celulose;

- $\quad$ E de origem animal como ossos e estercos.

Dessa forma, a qualidade do biochar depende de fatores associados ao processo térmico como taxa de aquecimento e temperatura, assim como a origem da biomassa (matéria-prima) utilizada (Batista, 2018). De acordo com Silva (2018), as matérias-primas de biomassa como gramíneas, cascas de grãos, palhas, estrume, produzem maiores concentrações de cinzas em relação a biocarvão de originados de madeira. Porém, segundo esse autor ainda, independente da biomassa utilizada, a temperatura elevada utilizada durante a pirólise proporciona uma alta porcentagem de cinzas no produto final. Desse modo, à medida em que há aumento da temperatura de pirólise, elementos como carbono $(\mathrm{C})$, oxigênio $(\mathrm{O})$, nitrogênio $(\mathrm{N})$, hidrogênio (H) e enxofre (S) são liberados em formas de gases, dificultando, por outro lado, a emissão de gases dos compostos inorgânicos.

Assim, este trabalho tem como objetivo verificar o estado da arte das pesquisas referentes ao biochar e sua aplicação, identificando as principais interações que ocorrem entre o biochar e o solo, bem como com os elementos que o compõem. De maneira mais específica, esta revisão busca analisar as culturas agrícolas e florestais que mais se beneficiam com a aplicação do biochar, busca verificar a influência do biochar na produção de biomassa e discute sobre o custo/benefício da implementação desse material no solo.

\section{Desenvolvimento}

O incremento da temperatura aplicada ao biochar propicia alterações na sua estrutura (Figura 1), de modo que na temperatura de $400{ }^{\circ} \mathrm{C}$ são encontradas elevações de carbonos aromáticos em interação com seu caráter amorfo, iniciando assim a presença de cadeias de grafeno poliaromático, lembrando folhas de caderno. Atribuindo mais temperatura, a quantidade de carbonos aromáticos é intensificada em decorrência da eliminação de compostos voláteis como água, hidrocarbonetos, alcatrão, $\mathrm{H}_{2}, \mathrm{CO}, \mathrm{CO}_{2}$, além da transformação para anel aromático. Por fim, por volta de $2500{ }^{\circ} \mathrm{C}$, o biochar se assemelha ao grafite, apresentando repulsão a água e uma estrutura ordenada/organizada (Batista, 2018). 
Research, Society and Development, v. 11, n. 2, e55711225999, 2022

(CC BY 4.0) | ISSN 2525-3409 | DOI: http://dx.doi.org/10.33448/rsd-v11i2.25999

Figura 1 - Desenvolvimento estrutural do Biochar com incremento de temperatura.

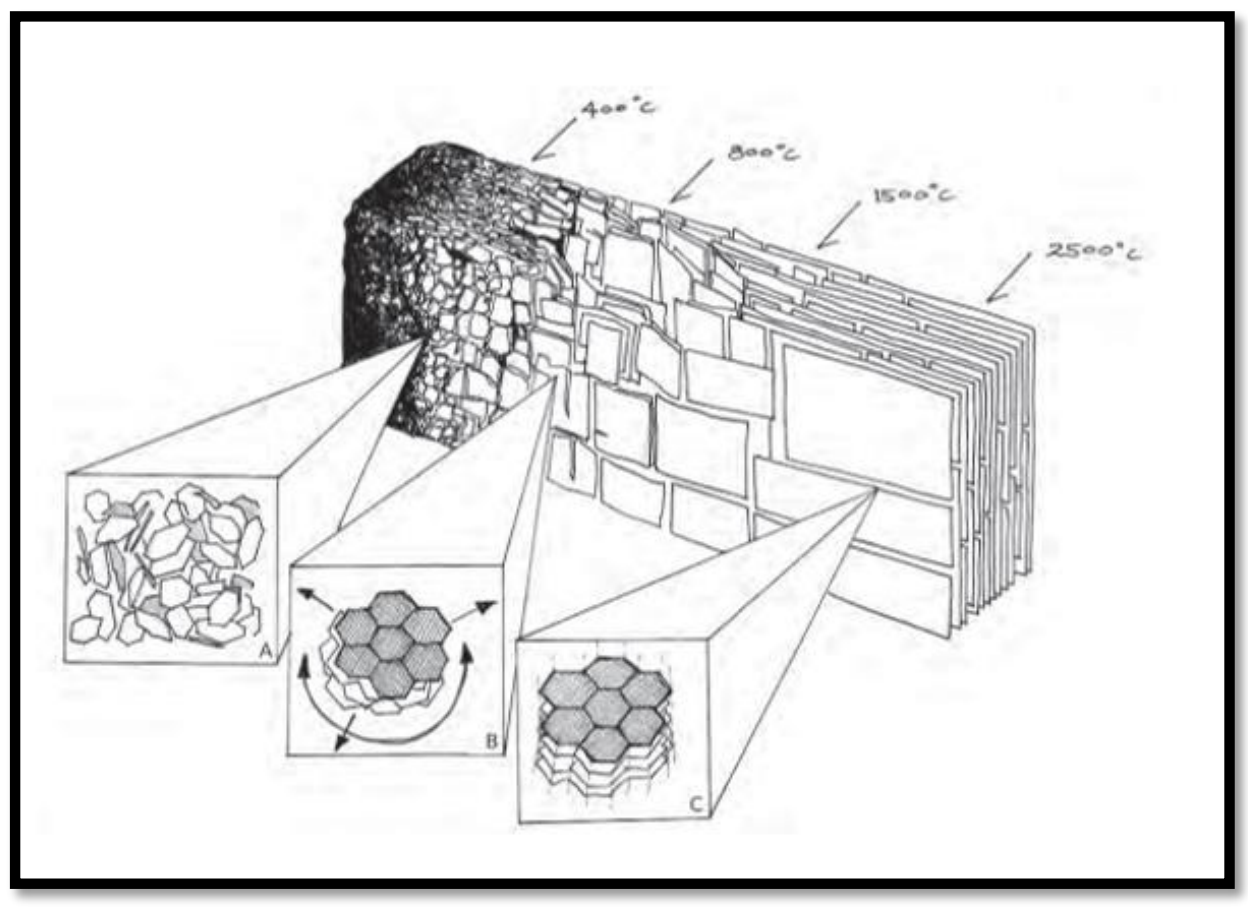

Fonte: Downie et al. (2012).

De acordo com Franco (2019), além de ser uma estrutura com empilhamento de grafeno e aromática organizada (Figura 2), em decorrência da eletronegatividade desses compostos aos carbonos são visualizados compostos químicos como oxigênio $(\mathrm{O})$, nitrogênio $(\mathrm{N})$, fósforo $(\mathrm{P})$ e enxofre $(\mathrm{S})$ ligados aos anéis benzênicos (aromático).

Figura 2 - Estruturação do Biocarvão: (A). Cristalinidade de grafite; (B). Aromatização apresentando O e radicais de carbono livres.

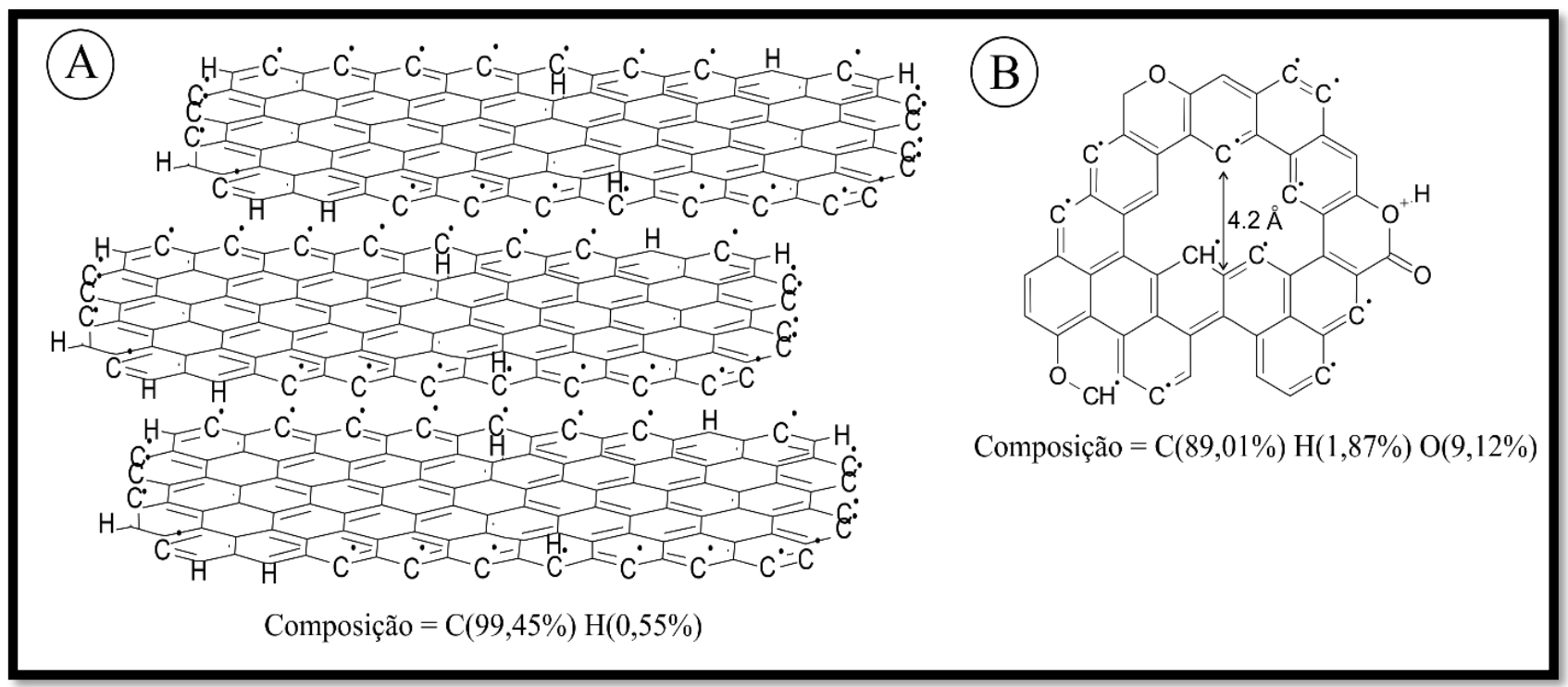

Fonte: Bourke et al. (2007) adaptada.

Consistindo em um produto onde sua qualidade depende dos diversos processos térmicos e do seu material de origem, o biochar, gera três formas de produto: o líquido, conhecido como bio-óleo; o sólido, o produto biochar desejado; e os gases não- 
condensáveis, rico em monóxido de carbono $(\mathrm{CO})$, dióxido de carbono $\left(\mathrm{CO}_{2}\right)$, metano $\left(\mathrm{CH}_{4}\right)$, entre outros compostos de hidrogênio e carbono (Trazzi et al., 2018).

De acordo com Bridgwater (2003), a classificação da pirólise pode ser das seguintes formas: Pirólise Rápida, Pirólise Lenta e Gaseificação (Tabela 1):

Tabela 1 - Diferentes Tipos de Pirólise, Características e Seus Respectivos Rendimentos.

\begin{tabular}{|c|c|c|c|c|}
\hline \multirow{2}{*}{ Tipos de Pirólise } & \multirow{2}{*}{ Características de Produção } & \multicolumn{3}{|c|}{ Rendimento (\%) } \\
\hline & & Líquido & Carvão & Gás \\
\hline Pirólise Rápida & $\begin{array}{l}\text { Temperatura moderada } \sim 500{ }^{\circ} \mathrm{C} \text {, curtos tempos de } \\
\text { residência dos vapores e biomassa }(<2 \mathrm{~s})\end{array}$ & 75 & 12 & 13 \\
\hline $\begin{array}{l}\text { Carbonização ou Pirólise } \\
\text { Lenta }\end{array}$ & $\begin{array}{c}\text { Baixas temperaturas }\left(400-450^{\circ} \mathrm{C}\right) \text {, tempo de } \\
\text { residência longo (horas ou dias) }\end{array}$ & 30 & 35 & 35 \\
\hline Gaseificação & $\begin{array}{c}\text { Alta temperatura }\left(<750^{\circ} \mathrm{C}\right) \text {, longo período de } \\
\text { residência }\end{array}$ & 5 & 10 & 85 \\
\hline
\end{tabular}

Fonte: Bridgwater (2003).

De acordo com Pereira (2019), as principais formas de pirólise são a lenta e rápida (Figura 3), tornando-os diferenciados devido ao intervalo de tempo de queima e dos seus respectivos produtos resultantes: a pirólise rápida, com temperaturas próximas a $500{ }^{\circ} \mathrm{C}$ com taxa de aquecimento de $100{ }^{\circ} \mathrm{C}^{-1}{ }^{-1}$ produz majoritariamente o bio-óleo, por exemplo, que pode ser útil em refinarias para ser transformado em combustíveis, adesivos ou até mesmo fertilizantes; a pirólise lenta, segundo esse autor ainda, com temperatura no intervalo de 350 a $750{ }^{\circ} \mathrm{C}$ e taxa de aquecimento em torno de $80{ }^{\circ} \mathrm{C} \cdot \mathrm{min}^{-1}$ é essencial na contribuição da parte sólida do biocarvão durante o processo de fabricação.

Figura 3 - Formas de Pirólise e Suas Respectivas Temperaturas e Características.

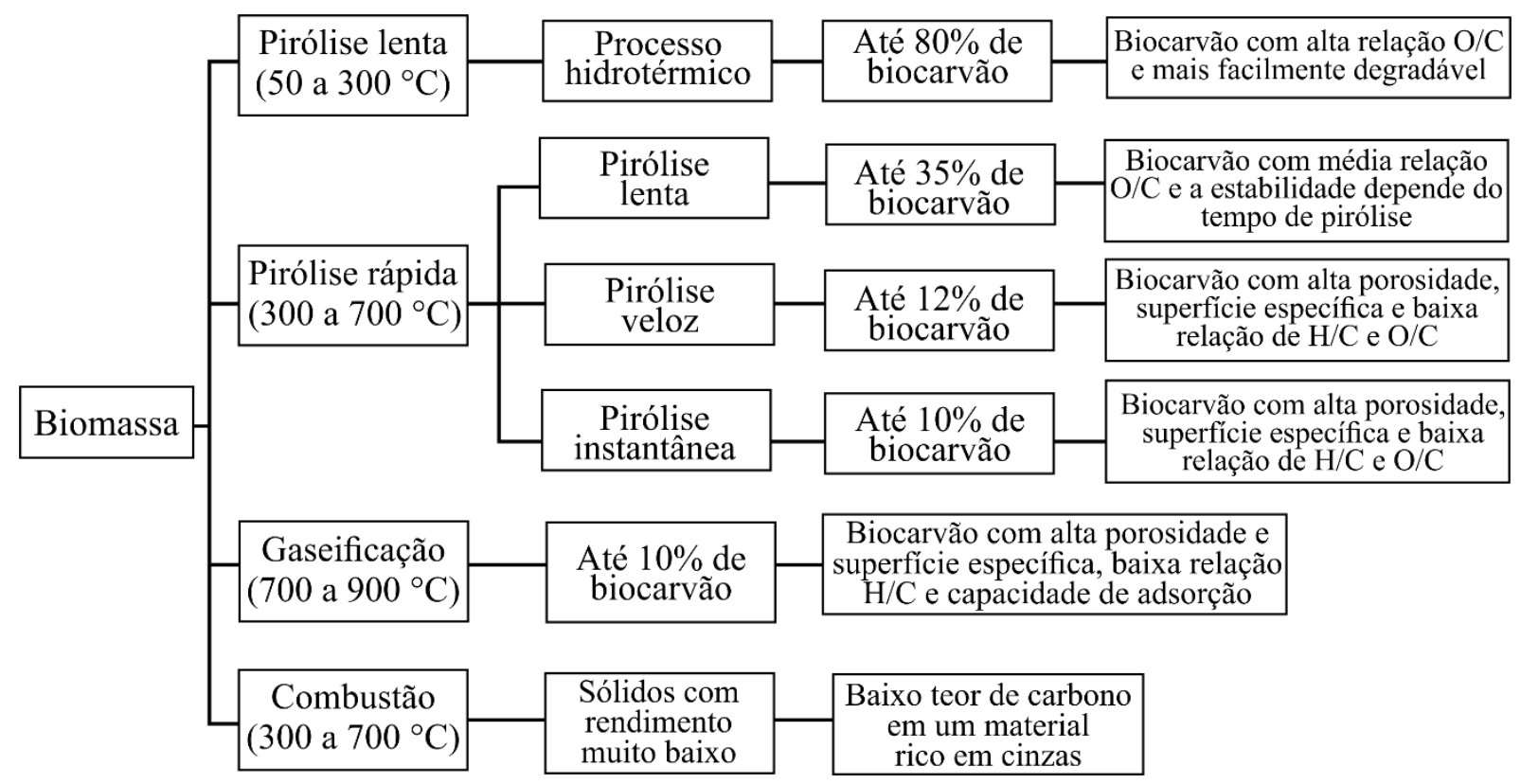

Fonte: Adaptado de Novotny et al. (2015).

A partir de determinadas temperaturas de pirólise, Bibar (2014), estabeleceu os seguintes rendimentos das biomassas (Tabela 2): 
Tabela 2 - Rendimentos (\%) de Biocarvões de diferentes biomassas submetidas a pirólise em temperaturas divergentes.

\begin{tabular}{cccc}
\hline Biomassa & Temperatura $\left({ }^{\circ} \mathbf{C}\right)$ & Matéria-prima (g) & Biocarvão (\%) \\
\hline \multirow{2}{*}{ Borra de Café } & 400 & 621,1 & 30 \\
& 700 & 637,8 & 16 \\
Dejeto de Galinha & 400 & 608,6 & 51 \\
\hline \multirow{2}{*}{ Lodo de Esgoto } & 700 & 639,6 & 45 \\
\hline Lodo de Esgoto Compostado & 400 & 776,5 & 68 \\
& 700 & 1002,3 & 59 \\
\hline \multirow{2}{*}{} & 400 & 1077 & 84 \\
\hline
\end{tabular}

Fonte: Adaptado de Bibar (2014).

Também conhecido como "carbono pirogênico", o biochar é uma matéria orgânica mais inerte, apresentando cor preta e com diversas cadeias aromáticas produzidas no processo de combustão. Dentre as diferenças entre biochar e carvão vegetal, está o fato da sua produção ser realizada com a finalidade de ser utilizado no solo, uma vez que o biochar tem maior média de vida no solo em comparações com outros materiais utilizados para melhorar as suas propriedades (Tenório, 2017).

Os materiais orgânicos para decomposição térmica do biochar diferenciam-se do carvão vegetal comum devido ao seu objetivo de ser utilizado para proporcionar caraterísticas (físicas, químicas e biológicas) melhores ao solo (Figura 4). As contribuições com isso podem ser a concentração de carbono no solo, diminuição de lixiviação de nutrientes e da contaminação do solo (Batista, 2016).

Figura 4 - Benefícios de aplicação de biochar.

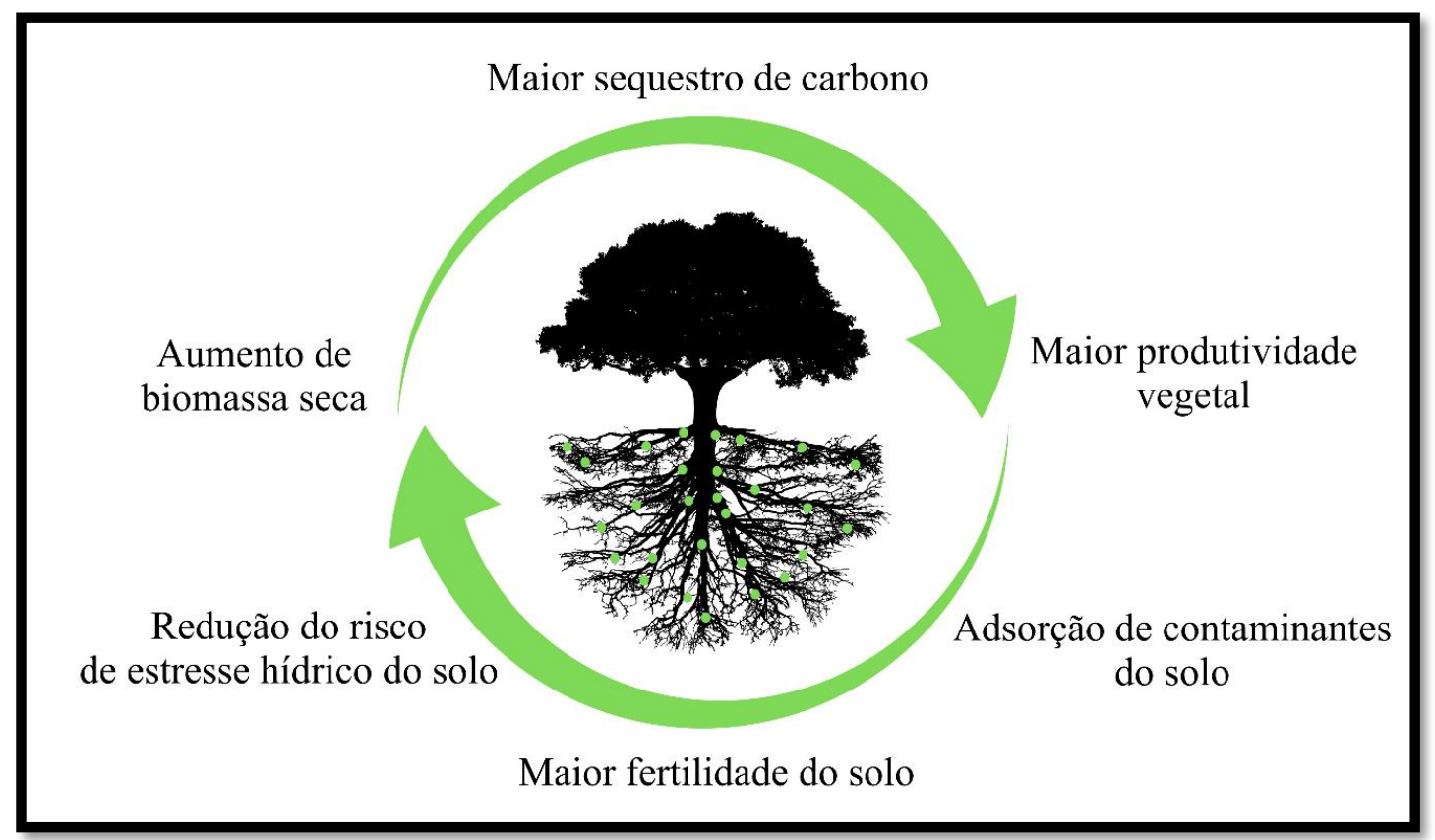

Fonte: Autores (2021).

De acordo com Guimarães (2017), o biochar proporcionar serviços ambientais como captura de carbono, diminuição de liberações de óxido nitroso $\left(\mathrm{N}_{2} \mathrm{O}\right)$, além de contribuir na fabricação dos biocombustíveis. Segundo esse autor ainda, para 
ocorrer o equilíbrio de matéria orgânica no solo é primordial a função como sequestrador de carbono atmosférico do biocarvão, dessa forma, contribuindo para elevação de produtividade nesses solos.

\section{Metodologia}

Para o desenvolvimento deste trabalho, foi realizada uma revisão de literatura sobre estudos relacionados ao uso do Biochar, classificada como uma pesquisa documental qualitativa (Pereira et al., 2018). Esta pesquisa foi realizada através da análise de documentos acadêmicos (artigos, dissertações e teses) disponíveis em repositórios digitais abertos, utilizando as seguintes plataformas: Google acadêmico, portal de periódicos CAPES, SCIELO e ScienceDirect. Para esta pesquisa, foram utilizadas palavras-chaves gerais, como "BIOCHAR", "BIOCHAR NO SOLO”, “CARVÃO NO SOLO”, "PRODUÇÃO DE BIOCHAR", bem como os respectivos termos traduzidos para a língua inglesa, no caso dos repositórios internacionais. Após a pesquisa inicial, foi realizada uma seleção dos trabalhos, com a leitura dos resumos, e foram selecionados os artigos/pesquisas que abordam de maneira experimental as temáticas avaliadas nesta revisão, compreendidas no intervalo dos anos de 2003 a 2021. Dessa forma, consiste em uma revisão de literatura sistemática, com o intuito de apresentar o estado da arte do uso do biochar como condicionador de solos, podendo ser obtidas vantagens na utilização desse produto, no ponto de vista ambiental, almejando a sustentabilidade.

\section{Resultados e Discussão}

\subsection{Histórico de utilização do biochar}

Os solos antropogênicos e o biochar apresentam semelhanças em seus processos de transformações, entretanto, a diferença dos solos antropogênicos consiste nas suas formações ao longo de séculos ou milênios. Na região Amazônica, formada pela decomposição de plantas e animais, localizavam-se índios nômades e o solo apresentava elevada fertilidade devido a armazenagem de biochar. Dessa forma, existem frações chamadas de "Terra Preta de Índio", com a alta capacidade de realização de troca catiônica, elevados teores de matéria orgânica rica em nitrogênio, fósforo, cálcio e potássio (Trazzi et al., 2018; Woiciechowski et al., 2018).

As "Terras Pretas de Índios" (TPI), formadas através de anos de ações antrópicas e deposição de material orgânico carbonizado, consistem em áreas de camadas superficiais do solo com coloração mais escura em relação a outras áreas próximas que são enriquecidas pela arqueologia como os pequenos pedaços de cerâmicas e outros materiais de civilizações antigas (Silva, 2018). Na Amazônia, as camadas de solos com elevada fertilidade devidas riquezas em cálcio, magnésio, zinco, manganês, fósforo e carbono com altas índices de pH e atividade biológica, são denominadas “Terra Preta", "Terra Preta de Índio" e "Terra Preta Arqueológica" carbono (Guimarães, 2017; Filho, 2017). De acordo com Assis (2018), os solos de Terra Preta da região central da Amazônia possuem aproximadamente três vezes de matéria orgânica, nitrogênio $(\mathrm{N})$ e fósforo $(\mathrm{P})$, além disso, apresenta superioridade imensa de carvão, cerca de 70 vezes mais, em relação aos solos nas proximidades.

Com essas riquezas, proporcionam ao solo concentrações de carbono de forma estável, assim, capacitando o solo com potencial adequado para sequestro de carbono (Guimarães, 2017; Filho, 2017). De acordo com Sánchez-Reinoso et al. (2020), os solos amazônicos apresentam índices de qualidade por apresentarem um horizonte A repleto de carbono oriundo do armazenamento de restos de animais e vegetais queimados durante a intensificação do fogo em tempos passados, consequências de atividades de queimadas realizadas por civilizações humanas passadas que moraram nessas regiões. Mas ainda não há um consenso entre os pesquisadores em relação às alterações no solo, se foram de maneira proposital ou se foram apenas depositando os resíduos carbonizados sem saber do seu potencial benéfico para o solo (Batista, 2016). 
De acordo com Novotny et al. (2015), a "Terra Negra da Amazônia" pode ser compreendida no contexto de responsabilidade dos pré-colombianos (nativos americanos) em ter melhorado os solos de forma planejada, porém isso ainda é uma hipótese incerta. Com isso, em relação a termos ou denominações, deve ser evitar a utilização de "biocarvão" para o "C pirogênico", observados na Terra Preta de Índios, em consequência dessa incerteza na intenção ou não de melhorias nos solos. Isso também deve ser evitado na denominação de "C pirogênico" em localidades sem a certeza de que os carvões encontrados no solo são originados de incêndios causados por ações humanas ou são originados de incêndios florestais.

Segundo Rebolledo et al. (2016), as Terras Negras possuem origens de queimadas intencionais ou acidentais, com intuito de eliminar as áreas florestadas e as ervas daninhas para implantar cultivos. Ademais, os solos das Terras Negras (ou Terra Preta de Índio) na Amazônia possuem semelhanças com solos apresentados no México e na África, assim como em Bornéu e Estados Unidos. Dessa forma, o holandês Wim Sombroek, em 1966, com seu trabalho "Solos da Amazônia", possibilitou a ideia de desenvolvimento de solos funcionando como armazéns para acúmulo de carbono para finalidade da agricultura intensa, denominando de "Terra New Black" (Figura 5).

Figura 5 - Comparação entre solos da Terra Preta de Índio e solos da Região Amazônica.

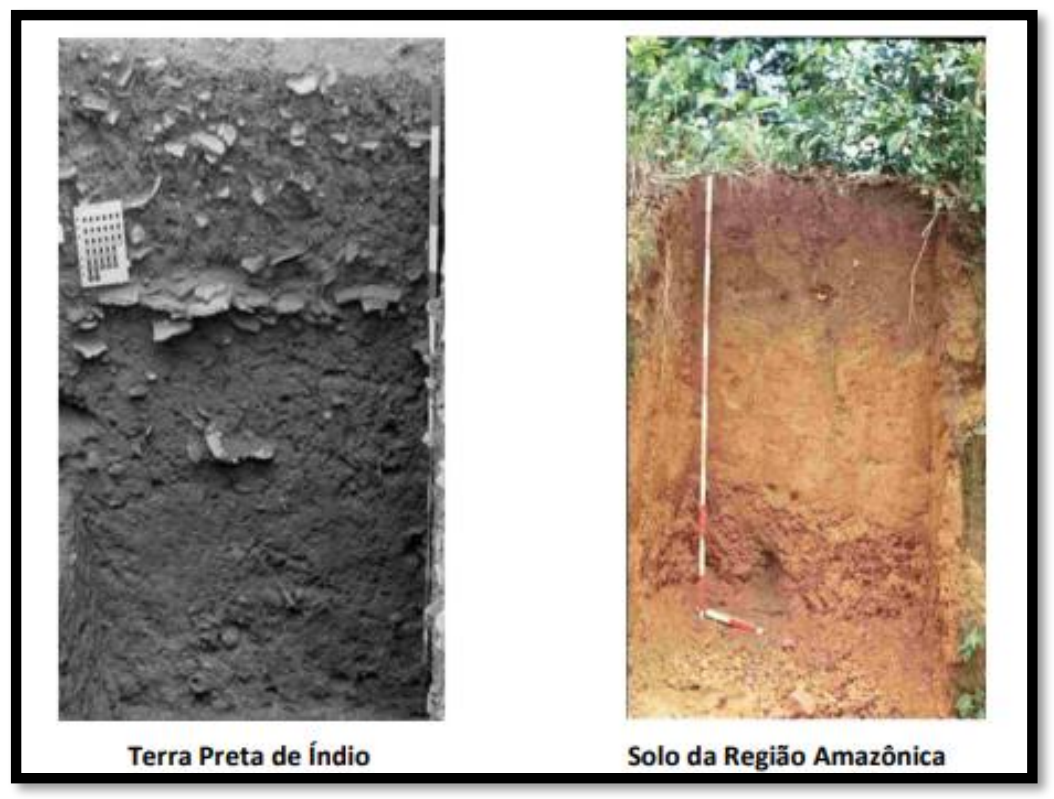

Fonte: Resende et al. (2011).

Como vimos, há diversas hipóteses em relação ao processo das Terras Pretas, porém, a mais aceitável se refere que sua formação seja oriunda de atividade antrópica. Através dessas atividades, como a pesca, foi mapeado solos com concentração de Terra Preta, possibilitado devido aos imensos rios fornecedores de comidas oriundas das embarcações que transitam na Amazônia, cuja maior concentração desses tipos de solos está entre as cidades de Manaus (Amazonas, Brasil) e Santarém (Pará, Brasil) (Guarnieri, 2016).

\subsection{Composição e estrutura química do biochar e principais propriedades físicas}

De acordo com o Lehamann e Joseph (2009), o biochar, em termos gerais, apresenta teor de carbono fixo entre 50 e $90 \%$, teor de material volátil entre 0 e $40 \%$, teor de umidade entre 1 e $15 \%$ e teor de cinzas de 0,5 a $5 \%$, que consistem em elementos químicos fundamentais à nutrição vegetal, tais como: cálcio $(\mathrm{Ca})$, potássio $(\mathrm{K})$ e Magnésio $(\mathrm{Mg})$, nos quais são em maior quantidade; e fósforo (P) em menor quantidade (Batista, 2018). 
Existem diferentes tipos de biochar com diferentes composições estruturais e químicas, dentro dos diferentes tipos, alguns podem apresentar características semelhantes como: coloração escura, $\mathrm{pH}$ (variando de neutro a básico), riqueza em carbono e apresentando um determinado nível aromático (Martins, 2018). De acordo com a metodologia da pirólise e a origem do material utilizado, essas as composições estruturais e químicas sofrem alterações em comparações entre os tipos de biochars (Martins, 2018).

O biochar é caracterizado por ter uma superfície dual, promovendo elevação da sua reatividade com outros elementos, ou seja, possui propriedades com atrações e repulsões a água, além de propriedades com caráter de pH ácido ou básico. Na pirólise, ocorre diversos eventos na área externa do biochar e na superfície dos poros como quebras de ligações químicas e rearranjos, dessa forma, produz grupos funcionais como: hidroxila, carboxila, aldeído, amenina, cetona, nitro e éster. Esses grupos têm a capacidade de participar na doação e recebimento de elétrons, considerando que os grupos ácidos são mais sensíveis a termodegradação (Batista, 2018).

O biochar possui uma estrutura amorfa, porosidade variando de micro $(<2 \mathrm{~nm})$, meso $(2-50 \mathrm{~nm})$ a macroporos $(>50$ $\mathrm{nm}$ ). Detalhadamente, os macroporos derivam-se dos espaços da matéria-prima de origem, contribuindo na velocidade de transporte dos sobartos em direção aos microporos. Esses, por sua vez, participam do carregamento de moléculas concentradas, sendo que essa granulometria pode produzir também cargas reativas e reter compostos nas fases líquidas, sólidas e gasosas (Rebolledo et al., 2016; Souza et al., 2020).

De acordo com Petter et al. (2016), devido a degradação térmica, o biochar (a base de madeira) sofre alterações nas suas propriedades físicas como a perda de massa e volume. Consequentemente, favorece o aparecimento dos poros macro, meso e microporos, elevando a sua área de superfície (Figura 6). Embora seja uma relação diretamente proporcional ao aumento da temperatura, aumentando a área de superfície específica (ou área de contato), por outro lado, ocorre a degradação ou volatização de compostos aromáticos, perda de carbono e redução na porosidade. Dessa forma, quando o biochar está enriquecido com materiais condensados de alcatrão e demais compostos de decomposição nos seus poros, sua capacidade de adsorção é comprometida, haja visto a ocupação desses sítios de ligação por outros elementos. Em contrapartida, perante a temperaturas elevadas e volatilização de tais compostos químicos, funciona como um atraente devido aos espaços porosos estarem livres.

Figura 6 - Imagem de alta resolução de biochar de madeira de eucalipto antes (A, B) e depois (C, D) da aplicação em um solo do tipo plintosolo háplico no bioma Cerrado.

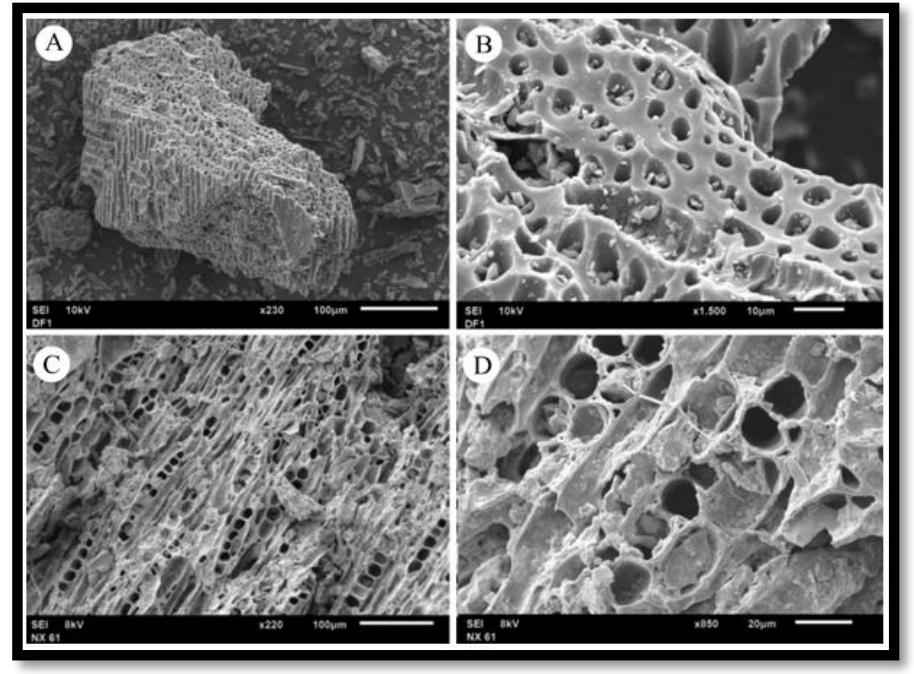

Fonte: Carvalho et al. (2014). 
As ligações químicas são essenciais para a estrutura do solo entre o biochar e moléculas macroscópicas inorgânicas (Figura 7), contribuindo assim para evitar que terrenos acidentais promovam desmoronamentos em condições de chuvosas acima do esperado. O funcionamento químico desse processo consiste na absorção da água precipitada, que, posteriormente será disponibilizada em condições de secas, onde os cátions (H+) e ânions ( $\mathrm{OH}-)$ são absorvidos e disponíveis no equilíbrio do $\mathrm{pH}$ do solo. Um exemplo prático pode ser considerado ao citar-se a captura de íons que são importantes e benéficos para a fisiologia das plantas como cálcio $(\mathrm{Ca})$, ferro $(\mathrm{Fe})$ e cobre $(\mathrm{Cu})$, entretanto, pode haver absorção de íons prejudiciais como o alumínio (Al) (Guimarães, 2017).

Figura 7 - (A) Esquema do Biochar com estrutura inerte e estrutura periférica funcionalizada; (B) Absorção da água; (C) Estruturando o solo; (D) Orientando os cátions e ânions para as plantas - como nutrientes e/ou sendo tóxico.

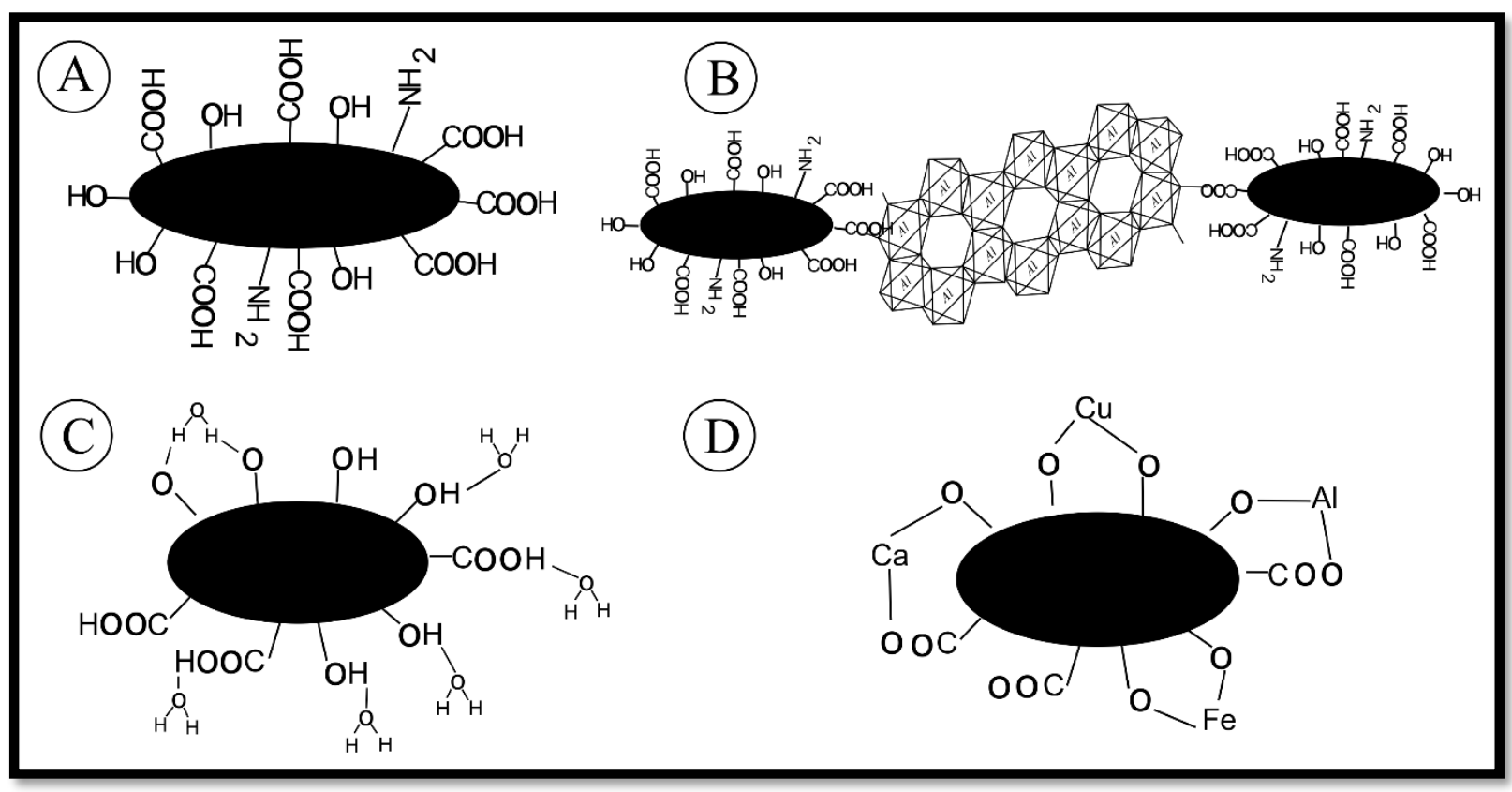

Fonte: Rezende et al. (2011).

O biochar proporciona estabilidade química ao solo, bem como uma diminuta variação do potencial hidrogênionico $(\mathrm{pH})$, que geralmente apresenta-se acima de 7. Embora sua matéria-prima seja originada de diversas fontes orgânicas e o seu processo de formação também possa ser diversificado, essas propriedades colaboram com elevada concentração de cadeias carbônicas e constantes ligações aromáticas fortes (Guimarães, 2017).

De acordo com pesquisa de Zhao et al. (2017) utilizando biochar oriundo de ramificações de indivíduos arbóreos, à medida que elevava a temperatura de pirólise, foi observada redução da quantidade de grupos funcionais ácidos como o ácido carboxílico, elevação da porosidade e aumento da área superficial. Ainda avaliando estas características, Souza et al. (2021) observaram que após um processo de oxidação do carvão vegetal de eucalipto, novos grupos funcionais oxigenados foram adicionados à superfície do material, o que aumentou, de maneira significativa, a capacidade de adsorção do biochar.

Através dos estudos de Novak et al. (2009), que analisaram a fertilidade de solos costeiros norte-americanos com características arenosas, ácidas, baixo teor de carbono e baixa CTC após a inclusão do biochar de casca de noz-pecã, houve elevação do pH do solo após 67 dias de incubação em uma casa de vegetação, elevação do carbono orgânico total bem como de outros nutrientes, como cálcio $(\mathrm{Ca})$, potássio $(\mathrm{K})$, manganês $(\mathrm{Mn})$ e fósforo $(\mathrm{P})$, e, consequentemente, a redução de ácido trocável do solo. 
Research, Society and Development, v. 11, n. 2, e55711225999, 2022

(CC BY 4.0) | ISSN 2525-3409 | DOI: http://dx.doi.org/10.33448/rsd-v11i2.25999

Silva (2017) conclui que o biochar a partir de casca de pequi é capaz de proporcionar alterações benéficas como a elevação do pH, diminuição do alumínio trocável e redução da acidez potencial, dessa forma, podendo ser útil na correção do solo.

\subsection{Efeitos positivos do biochar no solo}

Os efeitos positivos no âmbito químico e físico do biochar são determinados através de variáveis como a densidade do material pirolisado e seu tamanho, além da composição química do material, como o teor dos componentes orgânicos (holocelulose e lignina), bem como os componentes inorgânicos, como o cálcio $(\mathrm{Ca})$, magnésio $(\mathrm{Mg})$, carbonos inorgânicos e a quantidade de cinzas (Sánchez-Reinoso et al., 2020).

Os procedimentos de produção do biochar garantem novas ordens ou disposições dos átomos de carbono, acarretando no aumento da porosidade e, consequentemente, promove benefícios às propriedades químicas por meio da alta superfície de contato, como o aumento da capacidade de troca de cátions (CTC) e da adesão de nutrientes (Trazzi et al., 2018). Em relação a superfície de contato, segundo Song et al. (2014), durante os procedimentos de pirólise para obtenção do biochar, o aumento da temperatura promove redução de moléculas de água, formando os microporos e elevando área superficial do biochar em cerca de três vezes.

O biochar, através da elevação da sua capacidade de troca catiônica (CTC), possibilita a adsorção de nutrientes, proporcionado uma solução em relação à infertilidade de terras agricultáveis, ou seja, observa-se a grande importância nas atividades biogeoquímicas do solo (Guimarães, 2017). Além disso, influencia na redução da lixiviação do nitrogênio em águas localizadas em alturas subterrâneas, observando-se influências nas mudanças de propriedades dos solos, no âmbito químico, físico e biológico (Filho, 2017; Hung et al., 2017).

Segundo Li et al. (2017), por ser um material com alta concentração de carbono (aproximadamente 50\% de carbono), o biochar traz benefícios na qualidade do solo pelo fato de reduzir a lixiviação de nutrientes. Consequentemente, a intensidade de irrigação e o uso de fertilizantes podem ser reduzidos, favorecendo assim a vivência dos seres microbianos no solo. Outra importante funcionalidade desse material orgânico é a diminuição de liberação de gases do efeito estufa (GEE's) como o dióxido de carbono $\left(\mathrm{CO}_{2}\right)$, metano $\left(\mathrm{CH}_{4}\right)$ e óxido nitroso $\left(\mathrm{N}_{2} \mathrm{O}\right)$.

A aplicação de biochar favorece benefícios às propriedades físicas do solo ao proporcionar maior disponibilidade de água e de ar (oxigênio) ao sistema radicular das plantas que, por sua vez, podem elevar seu alcance de penetração no solo, quando comparado a um determinado solo sem a presença desse produto orgânico. De forma direta, sua presença influencia na elasticidade e permeabilidade edáfica, bem como na qualidade em absorção de íons positivos e melhores reações a mudanças de temperaturas. De forma indireta, afeta a fertilidade do solo através de forma química e biológica, além de disponibilizar formas de proteções à comunidade microbiológica (Guimarães, 2017).

Silva (2017), por sua vez, afirma que o biochar influencia na qualidade das propriedades físicas, biológicas e químicas pelo fato de proporcionar a diminuição da compactação do solo. Consequentemente, habilita a elevação do trânsito dos gases e gera maior conforto ao desenvolvimento das raízes de plantas, bem como o crescimento das comunidades de microrganismos no solo.

Os benéficos do biochar enumeram-se também pela neutralização da acidez do solo e aumento da produtividade dos plantios devido sua elevação da presença de nutrientes. Além das contribuições positivas nos fatores químicos, físicos e biológicos, há também o aspecto econômico, pois, possibilita o produtor reduzir seus custos devido à ausência de necessidade da utilização dos fertilizantes minerais convencionais (Schenider, 2015). A elevação de determinada produção agrícola e sua alta resistência a mineralização em relação a matéria orgânica estão relacionadas com o pH, no qual a inserção do biochar favorece a menor concentração de alumínio (Al) nos solos (Tenório, 2017). 
Research, Society and Development, v. 11, n. 2, e55711225999, 2022

(CC BY 4.0) | ISSN 2525-3409 | DOI: http://dx.doi.org/10.33448/rsd-v11i2.25999

Essa presença de $\mathrm{pH}$ básico é derivada de compostos oxigenados $\left(-\mathrm{O}^{-}\right.$e $\left.-\mathrm{COO}^{-}\right)$situadas na superfície do biochar, capazes de capturar $\mathrm{H}^{+}$, proporcionando assim caráter menos ácido ao solo (Sizmur et al., 2015). Outra forma de diminuir a acidez do solo são as aplicações de carbonatos, nos quais reagem com a água presente no solo. Além disso, aumentando a concentração de íons positivos como potássio $(\mathrm{K})$, sódio $(\mathrm{Na})$, cálcio $(\mathrm{Ca})$ e magnésio $(\mathrm{Mg})$, resíduos formados durante a pirólise são capazes de propiciar um caráter básico ao solo (Yuan et al., 2011 e Schenider, 2015). De forma detalhada, esses íons positivos disponibilizados ao solo irão preencher os espaços de cargas negativas, nos quais eram preenchidos com cargas de $\mathrm{H}^{+} \mathrm{e}^{+3}$, antes da aplicação dos compostos básicos, promovendo a neutralização sistema edáfico (Schenider, 2015).

Devido a sua estabilidade no solo e alto grau de porosidade, o biochar proporciona maior qualidade na capacidade de absorção hídrica. As reações entre os coloides de argilas e a matéria orgânica são influenciadas pelas disposições e disponibilidade dos componentes químicos da matéria orgânica, do seu grau de polaridade (positivo e negativo) e do seu teor de íons (cátions e ânions) no solo (Trazzi et al., 2018). De acordo com Batista (2018), o biochar pode beneficiar o solo através da elevação de disponibilidade de nutrientes, retenção hídrica, captura de carbono, consequentemente, contribuindo para a vida microbiana, redução da necessidade de fertilizantes, da liberação de gases do efeito estufa e de processos danosos aos solos, como a lixiviação e a erosão.

Em relação aos microrganismos, o biochar proporciona estabilidade elevada e proporciona a criação de habitat para esses organismos que vivem no solo, além da função de captura de carbono. Essa redução de emissões de gás carbônico garante agregados ao solo, de modo que a decomposição orgânica seja dificultada (Vendruscolo, 2015). Além disso, a mineralização do carbono ocorre de forma mais intensa, podendo beneficiar o desenvolvimento da microbiota e macrobiota (Vendruscolo, 2015).

O biochar funciona como equilibrador de emissões de gás carbônico, isto é, a pirólise da biomassa possibilita a estabilização de carbono, de forma a não ser volatilizado à atmosfera. Entretanto, sua concentração em excesso pode ser considerada um malefício ao solo e às plantas. Em usos agrícolas, onde apresentam baixa concentração de carbono, biochar pode ser adicionado em plantios diretos, em sistema de integração lavoura-pecuária-floresta (ILPF), reflorestamento e em recuperação de áreas degradadas (Cobra, 2015).

Segundo He et al. (2017), a partir da absorção de nutrientes, o biochar reduz a necessidade de fertilizantes ao longo do tempo, porém isso não seria viável sem seu alto grau de porosidade e superfície de contato específica. Tais características contribuem positivamente na forma de habitat para os microrganismos como bactérias e as micorrizas, que por sua vez, irão ter a função na decomposição da matéria orgânica e, consequentemente, provocando a ciclagem de nutrientes.

O crescimento e reprodução dos microrganismos são beneficiados pela sua nutrição rica em carbono e outros tipos de energia, além disso, qualificada pelas melhorias através da absorção hídrica do solo. Isso ocorre porque o biochar é rico também em nitrogênio, oxigênio, dessa forma entende-se o motivo dos desenvolvimentos das plantas, pois a presença desses elementos químicos favorece a retenção de nutrientes por esses vegetais, além das transformações e as fases bioquímicas no solo (Tan et al., 2017).

Portanto, quando inserido no solo, o biochar contribui na elevação do pH, CTC, carbono orgânico, fixação de nitrogênio, aumento no fornecimento de fósforo $(\mathrm{P})$, potássio $(\mathrm{K})$, cálcio (Ca), boro (B) e molibdênio (Mo), por outro lado, diminui as perdas desses nutrientes, devida a elevação de retenção de herbicidas (Trazzi et al., 2018).

Os microrganismos são protegidos dos seus predadores, alojando-se nos poros do biocarvão, nos quais também podem reter nutrientes inorgânicos, gases e matéria orgânica solúvel. Esse ambiente torna-se favorável para a resiliência da comunidade, crescimento e a reprodução de seres como as bactérias, fungos micorrízicos e actinomicetos. Outro fator que contribui para essa resiliência dos microrganismos é o poder da neutralização ácida no solo e absorção de nutrientes disponibilizados a eles (Filho, 2017). 
Os macroporos (> $200 \mathrm{~nm}$ ) geralmente habitam as bactérias $(0,3-3 \mu \mathrm{m})$, assim como os fungos $(2-80 \mu \mathrm{m})$ e os protozoários (7-30 $\mu \mathrm{m})$. Por sua vez, os microporos (<2 nm), juntamente como os mesoporos (2-50 nm) são os responsáveis por armazenar ar, água e outras substâncias orgânicas essências para o desenvolvimento e crescimento das microbiotas. As cargas do biochar, influenciam positivamente nesse desenvolvimento e crescimento da comunidade devido aumento da aderência dos seres microbianos às superfícies de contato específicas do biochar (Souza, 2016).

Em termos gerais, de acordo com Nóbrega (2011), as propriedades físico-químicas do biochar são capazes de interferir positivamente para o solo, sendo isso ocasionado nas propriedades como a porosidade, retenção hídrica, densidade, bem como no $\mathrm{pH}$, eletrostática e forças de capilaridade. Isso é benéfico porque esses fatores facilitam o enraizamento de forma mais profunda nos solos, dessa forma, absorvendo maior concentração hídrica e maior concentração de ar, resultando em desenvolvimento das plantas com maior êxito (Franco, 2019).

\subsection{Interação do biochar com fertilizantes e defensivos agrícolas}

Os pesticidas, conhecidos como contaminantes orgânicos, são inseridos no meio ambiente produzindo toxidade para os seres vivos, possibilitando também que as plantas os absorvam, ou que sejam infiltrados até alcançar o lençol freático. Entretanto, a utilização de componentes carbonáceos, como o biochar, é uma importante ferramenta na retenção dos compostos químicos como os pesticidas em decorrência da elevada área de superfície específica (SSA) e da sua aromaticidade oriunda dos anéis benzênicos. A parte física, como os microporos do biochar, têm a função de absorção e adsorção dos pesticidas (Souza, 2016).

Ainda nos âmbitos agronômicos, o biochar possui características que incluem elevada porosidade e capacidade de troca catiônica, aumento da resistência do solo a mudanças de pH e diversos grupos funcionais (Figura 8) os quais o credenciam para dar capacidades de adsorção de metais pesados despejados nos solos, seja ela de forma acidental ou intencional (Assis, 2018; Souza et al., 2021).

Figura 8 - Grupos funcionais ácidos e básicos de oxigênio em superfícies de contato do carbono.

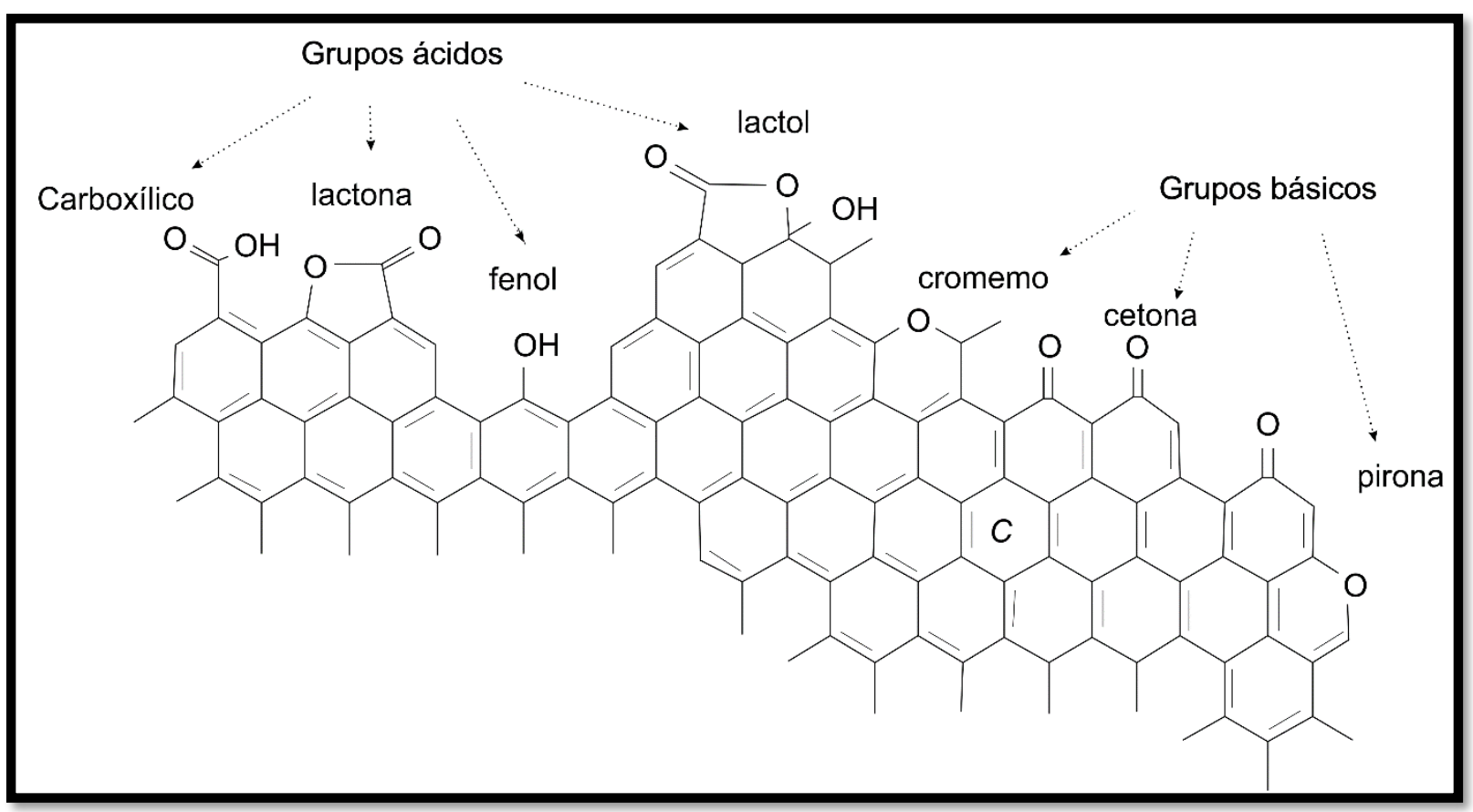

Fonte: Montes-Morán et al. (2004). 
O biochar é capaz de absorver elementos químicos como o arsênio (As), cádmio $(\mathrm{Cd})$, chumbo $(\mathrm{Pb})$, cobre $(\mathrm{Cu})$, cromo $(\mathrm{Cr})$, níquel $(\mathrm{Ni})$, zinco $(\mathrm{Zn})$, denominados de metais pesados. Essas substâncias são armazenadas no solo próximos de plantios em decorrência do uso exagerado de herbicidas, inseticidas e outros produtos (Sánchez-Reinoso et al., 2020).

Esses tipos de xenobióticos encontrados nos solos são bloqueados ou aderidos pelo biochar, reduzindo a disponibilidades desses compostos contaminantes e a toxidade às plantas e outras formas de vida no solo (Alves, 2016). Em outras palavras, a aplicação do biochar em solos agrícolas reduz os prejuízos tanto dos herbicidas como dos pesticidas nos quais são ricos em compostos químicos como os metais pesados. Esses metais podem ser lixiviados até alcançar o lençol freático, causando contaminação também dos seres humanos, trazendo malefícios no ciclo alimentar por causa da sua adsorção e baixa retenção de nutrientes (Muhammad et al., 2016).

Sánchez-Reinoso et al. (2020) observaram que o biochar originado de excremento bovino diminui a concentração de atrazina (herbicida de baixo custo) no solo e que o biochar tem capacidade de reter substâncias como clorpirifós e carbofurano de inseticidas, reduzindo ainda a quantidade de pentaclorofenol, presente em pesticidas. Estudos também apontam o biochar como adsorvente capaz de reduzir a concentração de compostos químicos e farmacêuticos, como o diclofenaco, furfural, glifosato, ibuprofeno, levafix vermelho, azul de metileno, naproxeno e sulfametazina (Igwegbe et al., 2021).

Jones et al. (2011), descrevem a inserção do biochar no solo, causando a decomposição da simazina (herbicida) e sua distribuição no solo, além da infiltração do pesticida. Esse reage com o biochar, produzindo a "Hotspost de pesticida”, ou seja, ocorre o armazenamento na superfície do solo, consequentemente, possibilitam uma ameaça para minhocas, ácaros, por exemplo, porém, estudiosos relatam que esse efeito negativo é muito raro. O pesticida, por sua vez, desacelera seu movimento em relação a precipitações, de forma a amenizar a possibilidade de toxidade nas águas do lençol freático (Jones et al., 2011).

O biochar é constituído de localizações específica para adsorção em diversas formas de reações, como os grupos ácidos $\left(\mathrm{H}^{+}\right)$e básicos $\left(\mathrm{OH}^{-}\right)$por meio das suas interações eletroestáticas (Figura 9). Essas interações são essências para as reações com íons (cátions e ânions) para absorção de nutrientes, como os fertilizantes, e/ou retirada de constituintes tóxicos como os pesticidas ou herbicidas, além disso, tais localizações específicas podem fazer ligações com a água e colóides orgânicos e inorgânicos se forem ativos (Ding et al., 2017).

Figura 9 - Relações por atração eletroestáticas (A) e a interação com os poros preenchidos (B).

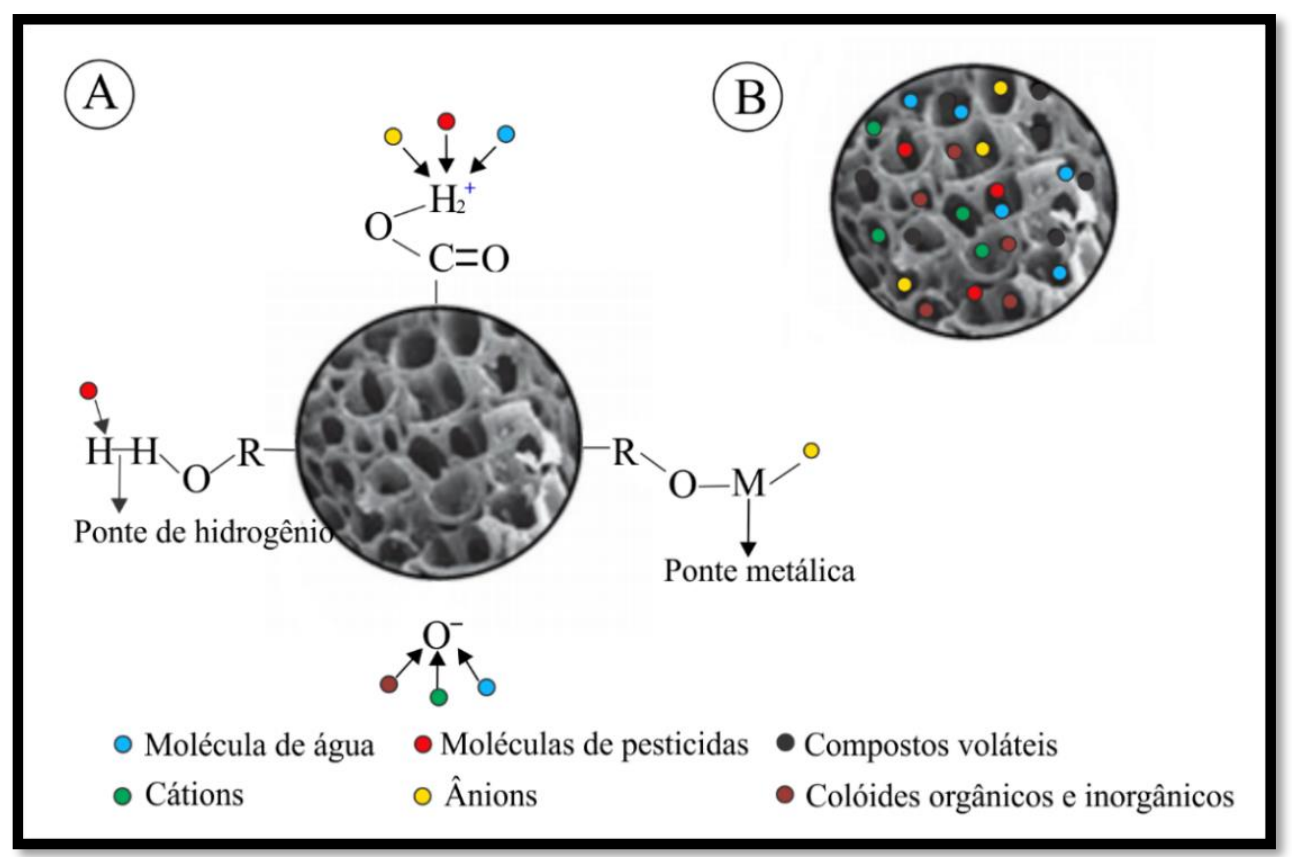

Fonte: Ding et al. (2017) adaptado. 
Research, Society and Development, v. 11, n. 2, e55711225999, 2022

(CC BY 4.0) | ISSN 2525-3409 | DOI: http://dx.doi.org/10.33448/rsd-v11i2.25999

A interação entre o fertilizante mineral convencional e o biochar possibilita elevação em potencial da retenção pelos vegetais, dessa forma, para engrandecer a sua produção, o produtor tem uma ótima alternativa. Além disso, ecologicamente falando, beneficia o ambiente capturando o carbono da atmosfera através do solo (Albuquerque et al., 2013).

\subsection{Dosagens recomendadas de biochar em função da cultura agrícola ou florestal}

Melo e Silva (2018), comparando substrato comercial (Bioplant) com concentrações diferentes de biochar (5\%, 10\%; $15 \%$ e $25 \%$ ) oriundo de pirólise do endocarpo e exocarpo do cafeeiro, obtiveram melhor resultado àquele que utilizava- Bioplant com $10 \%$ de biochar. Essa conclusão apresentou viabilidade, considerando que concentrações acima disso iriam trazer malefícios ao crescimento de plântulas de alfaces (Lactuca sativa L.).

Silva et al. (2017) analisando o crescimento e produção do feijão (Phaseolus vulgares L.), estruturaram os seguintes tratamentos: biochar a partir do filtro da casca de arroz (BRHF); biochar de filtro de serragem (BSF) e biochar a oriundo do filtro de silagem de sorgo (BSSF). Considerando o rendimento de cada carvão dada pela equação:

$$
\mathrm{R}(\%)=\frac{m}{f}
$$

Em que: $\mathrm{R}(\%)=$ Rendimento do biochar; $\mathrm{m}=$ massa; $\mathrm{f}=$ filtração do biochar massa material .

Além disso, cada tratamento apresentava cinco tipos de concentrações de biochar $(0 \%, 2.5 \%, 5 \% 7.5 \%$ e $10 \%$ v/v), sendo que as concentrações correspondiam respectivamente: $0,18.5,37.0,55.5$ e 74.0 $\mathrm{Mg}^{-1} \mathrm{de}^{-1} \mathrm{BRHF} ; 0,25.5,51.0,76.5 \mathrm{e}$ 102.0 $\mathrm{Mg} \mathrm{ha}^{-1}$ de BSF; e 0, 27.0, 54.0, 81.0 e 108.0 $\mathrm{Mg} \mathrm{ha}^{-1}$ de BSSF. Com isso, os autores concluíram que o biochar que as dosagens de 10\% de BRHF, 7\% de BSF e 7\% de BSSF apresentaram maior número de vagens, número de grãos e, ou seja, maior produção de massa seca de grãos.

Trazzi et al. (2018) relataram: Omil et al. (2013) concluíram que foi desnecessário a aplicação de fósforo (P) para o desenvolvimento, durante três anos, em plantação de Pinus radiata com idade de 13 anos. Isso foi possível devido a adubação com 4,5 t.ha ${ }^{-1}$ de cinzas e biochar disponibilizada por uma termoelétrica, considerando que os tratamentos com essa combinação evitaram lixiviação de nutrientes e elevaram o teor de matéria orgânica no solo; por sua vez, Petter et al. (2012) concluíram que biochar oriundo de eucaliptos com dose de 8 t.ha- ${ }^{-1}, 16$ t.ha ${ }^{-1}$ e 32 t.ha- ${ }^{-1}$ proporcionam fertilidade ao solo, produzido maior concentração de cálcio (Ca) e fósforo (P), tornando o pH elevado e elevando o carbono orgânico no campo; por fim, Major et al. (2010) aplicaram doses de biochar de refugos de madeira com 8 ou 20 t.ha $^{-1} \mathrm{em}$ solo, sendo que após quatro anos desse acontecimento, o solo apresentou elevação de pH, além do aumento da concentração de cálcio $(\mathrm{Ca})$ e magnésio $(\mathrm{Mg})$, por outro lado, diminui a acidez trocável.

Lima et al. (2015) pesquisando sobre o desenvolvimento de mudas da espécie florestal do cerrado conhecida como “tingui” (Magonia pubescens A. St.-Hil), apresentando metodologias: Teste (Latossolo Vermelho); CM10 (Latossolo Vermelho + esterco bovino a 10\%); CM20 (Latossolo Vermelho + esterco bovino a 20\%); CM30 (Latossolo Vermelho + esterco bovino a 30\%); BC20 (Latossolo Vermelho + biochar a 20\%); BC30 (Latossolo Vermelho + biochar a 30\%); CM10 + BC20 (Latossolo Vermelho + esterco bovino a 10\% + biochar a 20\%); CM20 + BC20 (Latossolo Vermelho + esterco bovino a 20\% + biochar a 20\%); CM30 + BC20 (Latossolo Vermelho + esterco bovino a 30\% + biochar a 20\%); CM10 + BC30 (Latossolo Vermelho + esterco bovino a 10\% + biochar a 30\%); CM20 + BC30 (Latossolo Vermelho + esterco bovino a 20\% + biochar a 30\%); e CM30 + BC30 (Latossolo Vermelho + esterco bovino a 30\% + biochar a 30\%). Nesse universo metodológico, as doses de 30\% onde apresentam esterco bovino e biochar são mais eficientes.

Woiciechowski et al. (2018), avaliando a disponibilidade de nutrientes, acidez e umidade do solo de plantios de Eucalyptus benthamii, utilizaram os tratamentos: T1 (sem biochar; sem adubação de base); T2 (10 Mg ha ${ }^{-1}$ de biochar; sem 
adubação de base); T3 (20 Mg ha-1 de biochar; sem adubação de base); T4 (40 $\mathrm{Mg} \mathrm{ha}^{-1}$ de biochar; sem adubação de base); T5 (sem biochar; com adubação de base); T6 (10 Mg de ha ${ }^{-1}$ biochar; com adubação de base); T7 (20 Mg ha ${ }^{-1}$ de biochar; com adubação de base); T8 (40 Mg ha-1 de biochar; com adubação de base). A partir disso, obtiveram destaque para a aplicação do T4 (40 Mg ha-1 de biochar; sem adubação de base), no qual aumentou a concentração no solo de bases trocáveis como potássio $(\mathrm{K})$, cálcio $(\mathrm{Ca})$, magnésio $(\mathrm{Mg})$, além do fósforo $(\mathrm{P})$. Isso foi possível devida alta presença de cinzas no biochar, sendo que isso foi benéfico na elevação do pH, dessa forma, decaindo a concentração de alumínio (Al) e sua acidez logo após 60 e 180 dias posteriores as suas aplicações.

Rezende et al. (2016) avaliando o desenvolvimento e qualidade das mudas de teca (Tectona grandis), tiveram como tratamentos: CS, composto por casca de pinheiro e vermiculita $(4: 1 \mathrm{~m} / \mathrm{m})$; NS, composto por casca de arroz carbonizada e fibra de coco (1:1 m/m); e misturas binárias de CS com biochar (BC) ou biochar ativado (BCA) a 25\%, 50\%, 75\% e 100\% - BC25, BC50, BC75, BC100, BCA25, BCA50, BCA75 e BCA100, respectivamente. Os autores concluíram que o biochar juntamente com o substrato comercial eleva o desenvolvimento das plântulas de teca, seja em altura como diâmetro do coleto. Considerando que o biochar com $25 \%$ + o substrato comercial apresentou os melhores resultados.

\subsection{Influência do biochar na produção de biomassa e principais aspectos da aplicação}

Trazzi et al. (2018) relataram em seu trabalho que Chan et al. (2007) elevaram sua produtividade do rabanete (Raphanus sativus) em massa seca por volta de $266 \%$, quando aplicaram $100 \mathrm{~kg} \cdot \mathrm{ha}^{-1}$ de fertilizantes nitrogenados em junto com 100 t.ha $^{-1}$ de biochar originado de resíduos agrícolas como poda, grama e algodão.

Pereira (2019), utilizando 2 biocarvões (biomassa oriunda de podas de mangueiras e biomassa originada de resíduos de processamento para suco de uva) e o carvão vegetal, em um delineamento experimental ao acaso com quatro repetições para a produção de biomasssa de milho, conclui que o resíduo de processamento de uva foi capaz de produzir maior matéria seca no

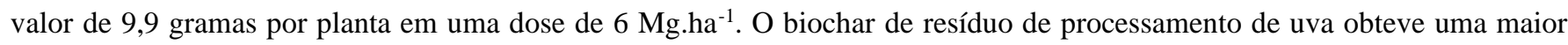
produção de matéria seca $\left(9,9 \mathrm{~g}\right.$ por planta) na dose de $6 \mathrm{Mg} \mathrm{ha}^{-1}$.

\subsection{Culturas agrícolas e florestais que mais se beneficiam com a aplicação do biochar}

Não existe uma tendência para espécies agrícolas ou florestais que fazem utilizações do biochar. Entretanto podemos citar estudos como: plantação de milho (Oguntunde et al., 2004), plantação de arroz (Major et al., 2012).

Pinto (2018) em sua pesquisa relatou: Andrade (2015) afirma um efeito positivo no desenvolvimento (crescimento e produção) em culturas de arroz e soja, bem como em mandioca, milho, pimentão e cana-de-açúcar; Shulz et al. (2013) estudando seis tipos de biocarvões, obtiveram resultados positivos em biomassa para espécie Avena sativa L.; Utilizando biochar oriundo de eucalipto, Petter et al. (2012), em conjunto com fertilizante (NPK), concluíram que os resultados com arroz de terras altas foram significativos no crescimento e armazenamento de biomassa seca; por sua vez, Santalla et al. (2011), estudando Pinus radiata com 25 anos de idade e após quatro após a aplicação de biochar e cinzas, perceberam desenvolvimentos tanto em altura como no seu diâmetro; por fim, Solla-Gullon et al. (2006), analisando cultura de Pseudotsuga menziesii (Pinheiro-do-Oregon), observaram elevação em altura de 5,4 a 16\% após quatro de sua aplicação de 10 e 20t.ha ${ }^{-1}$ contendo biochar oriundo de papel e celulose.

Rodrigues (2017), em sua pesquisa descreveu: Steiner et al. (2007) utilizando biochar de eucalipto junto com sulfato de amônia (fertilizante), obtiveram ótimos resultados na produtividade do arroz, considerado que tal solo era intemperizado; por sua vez, Carvalho et al. (2013), usando biochar em cultivo de arroz, teve efeitos nos grãos de arroz que mereceram destaque; Nunes et al. (2020), utilizando mudas da espécie florestal castanheira-do-pará (Bertholletia excelsa), apresentaram maiores desenvolvimento quando estavam inseridas em substratos contendo 30 e $50 \%$ de biochar; Souchie et al. (2015), analisando mudas 
Research, Society and Development, v. 11, n. 2, e55711225999, 2022

(CC BY 4.0) | ISSN 2525-3409 | DOI: http://dx.doi.org/10.33448/rsd-v11i2.25999

de carvoeiro (Tachigali vulgaris) alcançaram resultados positivos quando a aplicação de biochar nos substratos apresentavam concentração de $12.5 \%, 25 \%$ e $50 \%$.

Trazzi et al. (2018) em sua pesquisa relata o trabalho de Kloss et al. (2014), onde foi realizado análise de crescimento da mostarda (Sinapis alba L.), cevada (Hordeum vulgare L.) e trevo-vermelho (Trifolium pretense L.), utilizaram biocarvões originados de palha de trigo, cavacos de madeira e poda de vinhedo, nesse caso, apenas houve efeitos positivos em produtividade com a cevada, sendo que o tratamento que causou esse efeito foi os cavacos de madeira.

Em estudos realizados em quatro safras utilizando determinado biochar em conjunto com fertilizante a base mineral, resultou-se no dobro da produção de arroz e sorgo, considerando a comparação de quando era utilizado apenas o fertilizante mineral (Steiner et al., 2007). De acordo com a pesquisa de Batista (2018), concluíram que biochar produzidos a temperatura de $350^{\circ} \mathrm{C}$ seria uma possibilidade com potencial para elevar a quantidade hídrica no solo, além disso, proporcionando diminuição de condições maléficas as plantas como o estresse hídrico. Vale ressaltar que nessa pesquisa, utilizou-se como matéria-prima a biomassa oriunda de cascas de coco verde, bagaço de laranja, cachos de dendê, bagaço de cana, plantas de aguapé e resíduos de carvão.

\subsection{Máquinas e implementos para aplicação de biochar no solo}

O biochar não apresenta uma metodologia própria para sua aplicação no solo a partir de máquinas e implementos. Há uma oportunidade de mercado para o desenvolvimento de máquinas e implementos que realizem a aplicação do biochar no solo. Além disso, faltam estudos suficientes que avaliem a utilização ou adaptação de outras máquinas já consolidadas no setor agrícola e florestal para a aplicação do biochar. Assim, partindo do princípio da sua aplicação geralmente em associação com fertilizantes minerais, tomaremos como base a metodologia para esses fertilizantes.

Os tratores agrícolas são usados como distribuidores dos fertilizantes minerais, sendo auxiliadores com determinada tecnologia. Seu papel consiste em garantir tais aplicações em uma parcela, por exemplo, de forma menos heterogênea possível (Serrano et al., 2014). As máquinas agrícolas são diferenciadas, através da American Society of Agricultural and Biological Engeneers (norma D497-7) entre preparo primário e secundário. O preparo primário consiste em máquinas que realizam o trabalho classificado como "mais pesado", ou seja, proporcionam mudanças na forma física do solo com o propósito de quebrar as áreas do solo mais compactas na sua superfície. Esses serviços podem ser realizados por Arado de disco, arado de aiveca; Grade aradora; Subsolador e Paraplow fixo. Por outro lado, as máquinas secundárias são capazes de quebrar a agregação de enormes blocos oriundos do trabalho realizado pela máquina primária, dessa forma, tratando o solo com intuito de possibilitar a atividade do plantio. Pode ser exemplificadas as máquinas: Cultivadores, Grades niveladoras, Capinadores e Enxada rotativa (Okuno, 2016).

As máquinas distribuidoras de fertilizantes possuem marcas registradas a sua fonte de potência, modelo de mecanismo dosador e modelo de mecanismo distribuidor. As distribuidoras de fertilizantes trabalham em conjunto com máquinas ou implementos podem ser: sulcadores, subsoladores, semeadores, plantadoras e cultivadores. Por sua vez, as aplicadoras ou distribuidoras de fertilizantes enumeram-se: aplicadores a lanço, aplicador de fertilizantes de linhas individuais, aplicador de fertilizante de linhas conjugadas, aplicador manual de fertilizante e aplicador de corretivo em linhas (Nicolosi, 2011). É importante destacar que, como há um possível nicho de mercado crescente para a aplicação do biochar no solo, também há um potencial mercado disponível para a criação e adaptação de máquinas e implementos que realizem a aplicação desse produto. Países como o Brasil, que possuem tradição agrícola e florestal, podem ser potenciais consumidores destes equipamentos, gerando uma oportunidade de mercado que possibilitará a movimentação de quantidades significativas de recursos financeiros. 


\subsection{Custo/benefício da aplicação do biochar no solo}

O biochar, além de contribuir no sequestro de carbono, melhora a nutrição do solo e, em consequência disso, melhora também a produtividade, promovendo alta capacidade de aumentar a lucratividade dos produtores/agricultores (Sánchez-Reinoso et al., 2020). Souza et al. (2006), analisando a produtividade de crajiru (Arrabidea chica), obteve vantagens na aplicação de biochar oriundo de estrume de frango, como a diminuição de resíduos e o principal, reduziu também os custos dos agricultores. No entanto, ainda são escassos estudos em grande escala que avaliem, detalhadamente, a viabilidade econômica da aplicação do biochar no solo em diferentes culturas.

De acordo com Trazzi et al. (2018), para avaliar a viabilidade econômica do biochar deve-se considerar os custos de produção do plantio, matéria de origem e o deslocamento de um determinado local para outro. Além disso, vale salientar que o biochar é indicado como um condicionador do solo e potencial para utilização ao invés do calcário. Segundo Blackwell et al. (2010), o custo da inserção do biochar no solo pode ser considerado lucrativo apenas com um investimento delimitado até \$ 170/ha, possibilitando elevação na produtividade aproximadamente de 10\% durante doze anos.

Harsono et al. (2013) apresentaram um potencial econômico na produção do biochar de, aproximadamente, 532,00 US\$/ano, considerando a receita total com sua comercialização de 8.012 US\$/ano (Tabela 3). Dessa forma, proporcionou um valor presente líquido da produção do biochar, de acordo com o valor do investimento e da receita líquida, sendo assim, disponibilizando efeitos positivos econômicos no uso do biochar.

Tabela 3 - Análise econômica da produção de biochar.

\begin{tabular}{ccc}
\hline Parâmetro & Unidade & Valor (aproximadamente) \\
\hline Investimento & US \$ & 1266,00 \\
\hline Valor Restante & US \$ & 126,00 \\
\hline Custo Total & US \$ / ano & 524,00 \\
\hline Custo Fixo Total & US \$ / ano & 170,00 \\
\hline Receita Total & US \$ / ano & 532,00 \\
\hline Custo Variável & US \$ / ano & 354,00 \\
\hline Valor Presente Líquido (VPL) & US \$ & 130,00 \\
\hline Ponto de Equilíbrio & Toneladas do Biochar & 901,00 \\
\hline Relação Custo / Benefício & - & 1,00 \\
\hline Taxa Interna de Retorno & $\%$ & 8,96 \\
\hline Período de Retorno & Ano & 9,97 \\
\hline Retorno do Investimento & $\%$ & 17,59 \\
\hline
\end{tabular}

Fonte: Harsono et al. (2013).

Por sua vez, Shabangu et al. (2014), o custo-benefício da fabricação do biochar era dependente do seu preço na comercialização, sendo que o ponto de equilíbrio era de US\$ 220/ton para uma pirólise de $300^{\circ} \mathrm{C}$, por outro lado, aproximadamente US\$280/ton para pirólise de $450^{\circ} \mathrm{C}$.

\section{Conclusão}

Independente da origem de sua matéria-prima, o biochar apresenta capacidade na retenção de substâncias que compõem os defensivos agrícolas (arsênio, cádmio, chumbo, cobre, cromo, níquel, zinco), possibilitando a diminuição de contaminação ambiental. Além disso, tem potencial elevado na produtividade quando combinado com outro tipo de fertilizante. A dosagem 
Research, Society and Development, v. 11, n. 2, e55711225999, 2022

(CC BY 4.0) | ISSN 2525-3409 | DOI: http://dx.doi.org/10.33448/rsd-v11i2.25999

pode variar de acordo com sua unidade de medida e também a sua área utilizada. Dessa forma, concentrações entre 7\% a 30\% de biochar, utilizadas em conjunto com determinado tipo de fertilizante mineral ou orgânico, obtiveram ótimos resultados. A biomassa da cultura após a inserção do biochar eleva-se 5 vezes em relação quando não ocorre o uso do biochar. As culturas agrícolas e florestais que se beneficiam são o milho, arroz, soja, mandioca, pimentão, cana-de-açúcar, mostarda, cevada, trevovermelho, Pinus radiata, Pseudotsuga menziessi, castanheira-do-pará, e Tachigali vulgaris.

No Brasil, ainda são escassos estudos relacionados às máquinas e implementos agrícolas utilizados para a aplicação do biochar no solo, indicando que há uma oportunidade de pesquisas neste setor que vem se mostrando promissor. Além disso, estudos que avaliem a viabilidade econômica do biochar em diferentes cenários não são facilmente encontrados, o que dificulta as possibilidades de investimento por meio do setor florestal e agrícola. Esta falta de estudos robustos se mostra como uma oportunidade para que pesquisadores da área de economia florestal possam desenvolver trabalhos em parceria com pesquisadores da área da silvicultura e dos solos e, a partir disso, forneçam informações precisas sobre os investimentos necessários e os retornos reais ao utilizar este produto.

Assim, observa-se uma vasta importância do biocarvão para a sociedade, bem como o meio-ambiente, sendo recomendado o aumento de pesquisas relacionadas as espécies florestais nativas e exóticas, além disso, enfatiza-se o início do uso de metodologias próprias a aplicação do biocarvão no solo através de implementos e máquinas. Por fim, recomenda-se também mais aprofundamento ou detalhamento em estudos baseados nos investimentos necessários para aplicação do biocarvão, observando seus custos e lucros, visto que, é uma oportunidade importante em caráter ambiental, podendo ser uma oportunidade econômica promissora os para produtores rurais.

\section{Referências}

Albuquerque, J. A., Salazar, P., Barrón, V., Torrent, J., Campillo, M. C., Gallardo, A., \& Villar, R. (2013). Enhanced wheat yield by biochar addition under different mineral fertilization levels. Agron. Sustain. Dev., 33, 475-484. 10.1007/s13593-012-0128-3

Alves, O. R., Bandeira, O. A., Borges, A. A., Prado, R. M., \& Pasqualetto, A. (2016). Biotecnologias de remediação de solos contaminados com agroquímicos. Agrarian Academy - Centro Científico Conhecer, 3 (5), 27-50. 10.18677/Agrarian_Academy_2016_003

Andrade, C. A. de., Bibar, M. P. S., Coscione, A. R., Pires, A. M. M., \& Soares, A. G. (2015). Mineralização e efeitos de biocarvão de cama de frango sobre a capacidade de troca catiônica do solo. Pesq. agropec. bras., 50 (5), 407-416. https://doi.org/10.1590/S0100-204X2015000500008

Assis, W. S. (2018). Efeito da adição de biocarvão de dejeto de suíno a um Neossolo Quartzarênico na sorção de zinco e cádmio (Dissertação de mestrado). Universidade Federal de Mato Grosso, Cuiabá, Mato Grosso, Brasil.

Batista, E. M. C. C. (2018). Biochar como ligante macromolecular no solo visando aumentar a capacidade de retenção de água nos solos do nordeste do brasil (Tese de doutorado). Universidade Federal do Paraná, Curitiba, Paraná, Brasil. https://hdl.handle.net/1884/59431

Batista, N. S. (2016). Diversificação de cultivos de hortaliças associada ao uso de insumos para a fertilidade do solo, em sistema orgânico de produção (Dissertação de mestrado). Universidade Federal Rural do Rio de Janeiro, Seropédica, Rio de Janeiro, Brasil. https://tede.ufrrj.br/jspui/handle/jspui/1774

Bibar, M. P. S. (2014). Potencial agrícola de biocarvão proveniente de biomassas alternativas. (Dissertação de mestrado). Instituto Agronômico, Campinas, São Paulo, Brasil.

Blackwell, P., Krull, E., Butler, G., Herbert, A. \& Solaiman, Z. (2010). Effect of banded biochar on dryland wheat production and fertiliser use in south-western Australia: an agronomic and economic perspective. Australian Journal of Soil Research, 48, 531-545. https://doi.org/10.1071/SR10014

Bourke, J., Harris, M. M., Fushimi, C., Dowaki, K., Nunoura, T., \& Antal, M. J. (2007). Do all carbonized charcoals have the same structure? A model of the chemical structure of carbonized charcoal. Industrial and Engineering Chemistry Research, 46, 5954-5970. https://doi.org/10.1021/ie070415u

Bridgwater, A. V. V. (2003). Renewable fuels and chemicals by thermal processing of biomass. Chemical Engineering Journal, 91(2-3), 87-102. https://doi.org/10.1016/S1385-8947(02)00142-0

Carvalho, M. T. M., Maia, A. H. N., Madari, B. E., Bastiaans, L., Van Oort, L. P. A., Heinemann, A. B., \& Meinke, H. (2014). Biochar increases plant-available water in a sandy loam soil under an aerobic rice crop system. Solid Earth, 5, 939-952.

Chan, K. Y., Zwieten, L. V., Meszaros, I., Downie, A., \& Joseph, S. (2007). Agronomic values of greenwaste biochar as a soil amendment. Australian Journal of Soil Research, 45, 629-634. https://doi.org/10.1071/SR07109 
Cobra, R. L. (2015). Avaliação do tratamento de efluentes líquidos integrado à recuperação de solos e produção de biomassa vegetal por meio do cultivo do capim vetiver (chrysopogon zizanioides (linnaeus) roberty) em solo adicionado de biocarvão (Dissertação de mestrado). Universidade Federal de São João DelRei, Ouro Branco, Minas Gerais, Brasil. https://locus.ufv.br//handle/123456789/10425

Ding, Y., Liu, Y. G., Liu, S. B., Huang, X. X., Li, Z. W., Tan, X. F., \& Zhou, L. (2017). Potential benefits of biochar in agricultural soils: a review. Pedosphere, 27 (4), 645-661. 10.1016/S1002-0160(17)60375-8

Downie, A., Munroe, P., Cowie, A. L., \& Zwieten, L. V. (2012). Biochar as a geoengineering climate solution: hazard identification and risk management. Critical Reviews in Environmental Science and Technology, 42 (3), 225-250. https://doi.org/10.1080/10643389.2010.507980

Filho, A. P. M. (2017). Impacto do biochar de café sobre as atividades enzimáticas e biomassa microbiana em neossolo cultivados com milho e feijão (Dissertação de mestrado). Universidade Federal Rural de Pernambuco, Garanhuns, Pernambuco, Brasil. http://www.tede2.ufrpe.br:8080/tede2/handle/tede2/8018

Franco, M. H. R. (2019). Biochar e fertilizantes especiais no crescimento inicial da cultura do milho (Tese de doutorado). Universidade Federal de Uberlândia, Uberlândia, Minas Gerais, Brasil. https://repositorio.ufu.br/handle/123456789/26428

Guarnieri, S. F. (2016). Alteração de atributos do solo devido ao emprego de biocarvão de frutos de cocos nucifera L. (Dissertação de mestrado). Universidade Federal do Mato Grosso, Cuiabá, Mato Grosso, Brasil.

Guimarães, R. S. (2017). Efeito do biocarvão e pó de serra na disponibilidade de nutrientes, crescimento e na produção de milho (Zea mays L.) em Latossolo Amarelo distrófico na Amazônia Central (Dissertação de mestrado). Instituto Nacional de Pesquisas Amazônicas, Manaus, Amazonas, Brasil. https://repositorio.inpa.gov.br/handle/1/5356

Harsono, S. S., Grundman, P., Lau, L. H., Hansen, A., Salleh, M. A. M., \& Meyer-Aurich, A. (2013). Energy balances, greenhouse gas emissions and economics of biochar production from palm oil empty fruit bunches. Resour. Conserv. Recycl., 77, 10-15. http://dx.doi.org/10.3390/pr8101275

He, L. L., Zhong, Z. K., \& Yang, H. M. (2017). Effects on soil quality of biochar and straw amendment in conjunction with chemical fertilizers. Journal of Integrative Agriculture, 16, 704-712. 10.1038/s41598-019-52978-w

Hung, C. Y., Tsai, W. T., Chen, J. W., Lin, Y. Q., \& Chang, Y. M. (2017). Characterization of biochar prepared from biogas digestate. Waste Management, 66, 53-60.

Igwegbe, C. A., Aniagor, C. O., Oba, S. N., Yap, P. S., Iwuchukwu, F. U., Liu, T., \& Ighalo, J. O. (2021). Environmental protection by the adsorptive elimination of acetaminophen from water: A comprehensive review. Journal of Industrial and Engineering Chemistry, 104, 117-135. https://doi.org/10.1016/j.jiec.2021.08.015

Jones, D. L., Edward-Jones, G., \& Murphy, D. V. (2011). Biochar mediated alterations in herbicide breakdown and leaching in soil. Soil Biology \& Biochemistry, 43, 804-813. 10.1016/j.soilbio.2010.12.015

Kloss, S., Zehetner, F., Wimmer, B., Buecker, J., Rempt, F., Soja, G. (2014). Biochar application to temperate soils: effects on soil fertility and crop growth under greenhouse conditions. Journal of Plant Nutrition and Soil Science, 177 (1), 3-15. https://doi.org/10.1002/jpln.201200282

Lehmann, J., \& Joseph, S. (2009). Biochar for Environmental Management: An Introduction. Science And Technology, 1, 1-12.

Li, H., Dong, X., Silva, E. B., Oliveira, L. M., Chen, Y., \& Ma, L. Q. (2017). Mechanisms of metal sorption by biochars: Biochar characteristics and modifications. Chemosphere, 178, 466-478. 10.1016/j.chemosphere.2017.03.072.

Lima, S. L., Tamiozzo, S., Palomino, E. C., Petter, F. A., \& Marimon-Júnior, B. H. (2015). Interactions of biochar and organic compound for seedlings production of Magonia pubescens A. St.-Hil. Revista Árvore, 39 (4), 655-661. https://doi.org/10.1590/0100-67622015000400007

Major, J., Rondon, M., Molina, D., \& Riha, S. (2010). Maize yield and nutrition during 4 years after biochar application to a Colombian savanna Oxisol. Plant and Soil, 333, 117-128. 10.1007/s11104-010-0327-0

Major, J., Rondon, M., Molina, D., Riha, S.J., \& Lehmann, J. (2012). Nutrient leaching in a Colombian savanna Oxisol amended with biochar. Journal of Environmental Quality, 41 (4), 1076-1086. 10.2134/jeq2011.0128

Martins, C. C. (2018). Biochar, composto orgânico e potássio nas características químicas e lixiviação de nutrientes em Espodossolo e no cultivo de mucuna preta e moringa (Tese de doutorado). Universidade Estadual do Norte Fluminense Darcy Ribeiro - Centro de Ciências e Tecnologias Agropecuárias, Campos dos Goycatazes, Rio de Janeiro, Brasil.

Melo, E. I., \& Silva, L. F. V. (2018). Biocarvão como condicionador de substrato para produção de mudas de alface. Revista Agropecuária Técnica, 39 (2), 107111. https://doi.org/10.25066/agrotec.v39i2.38692

Montes-Morán, M. A., Suárez, B., Menéndez, J. A., \& Fuente, E. (2004). On the nature of basic sites on carbon surfaces: An overview. Carbon, 42, 1219- 1225. $10.1016 /$ S0008-6223(04)00014-4

Muhammad, N., Brookes, P. C., \& Wu, J. (2016). Addition impact of biochar from different feed stocks on microbial community and available concentrations of elements in a Psammaquent and a Plinthudult. Journal of Soil Science and Plant Nutrition, 16 (1), 137-153. http://dx.doi.org/10.4067/S071895162016005000010

Nicolosi, M. M. (2011). Planejamento de qualidade de aplicação a lanço em taxa variável (Dissertação de mestrado). Universidade de São Paulo (Escola Superior de Agricultura "Luiz de Queiroz"), Piracicaba, São Paulo, Brasil.

Nóbrega, I. P. C. (2011). Efeitos do biochar nas propriedades físicas e químicas do solo: Sequestro de Carbono no solo (Dissertação de mestrado). Universidade Técnica de Lisboa, Lisboa, Portugal. http://hdl.handle.net/10400.5/4104 
Research, Society and Development, v. 11, n. 2, e55711225999, 2022

(CC BY 4.0) | ISSN 2525-3409 | DOI: http://dx.doi.org/10.33448/rsd-v11i2.25999

Novak, J. M., Busscher, W. J., Laird, D. L., Ahmedna, M., Watts, D. W., \& Niandou, M. A. S. (2009). Impact of biochar amendment on fertility of a southeastern coastal plain soil. Soil Science, 174 (2), 105-112. 10.1097/SS.0b013e3181981d9a

Novotny, E. H., Hayes, M. H. B., Madari, B. E., Bonagamba, T. J., De Azevedo, E. R., De Souza, A. A., \& Mangrich, A. S. (2009). Lessons from the Terra Preta de Índios of the Amazon Region for the Utilisation of Charcoal for Soil Amendment. Journal of the Brazilian Chemical Society, 20 (6), $1003-1010$. https://doi.org/10.1590/S0103-50532009000600002

Novotny, E. H., Maia, C. M. B. F., Carvalho, M. T. M., \& Madari, B. E. (2015). Biochar: Pyrogenic carbono for africultural use - A critical review. Revista Bras. Ci. Solo, 39 (2), 321-344. https://doi.org/10.1590/01000683rbcs20140818

Nunes, M. M., \& Teixeira, W. G. Crescimento de mudas de castanheira-do Brasil (Bertholletia excelsa H. B. K.) em função de doses de carvão vegetal como componentes de substrato. In: Reunião Cientifica da Rede Ctpetro Amazônia, 3, Manaus. Anais... Manaus: Petro Amazônia, 2010.

Oguntunde, P. G., Fosu, M., Ajayi, A. E., \& Giesen, N. V. (2004). Effects of charcoal production on maize yield, chemical properties and texture of soil. Biology and Fertility of Soils, 39 (4), 295-299. 10.1007/s00374-003-0707-1

Okuno, M. T. (2016). Máquina conceito de preparo do solo em faixas (Dissertação de mestrado). Universidade Estadual de Campinas, Campinas, São Paulo, Brasil. http://repositorio.unicamp.br/jspui/handle/REPOSIP/321168

Omil, B., Piñeiro, V., \& Merino, A. (2013). Soil and tree responses to the application of wood ash containing charcoal in two soils with contrasting properties. Forest Ecology and Management, 295, 199-212. 10.1016/j.foreco.2013.01.024

Oni, B. A., Oziegbe, O., \& Olawole, O. O. (2019). Significance of biochar application to the environment and econom. Annals of Agricultural Sciences, 64, 222236. $10.1016 /$ j.aoas.2019.12.006

Pereira, J. R. C. (2019). Potencial do biocarvão para a produção de milho e melhoria da qualidade do solo (Dissertação de mestrado). Universidade de Pernambuco, Petrolina, Pernambuco, Brasil

Pereira, A. S., Shitsuka, D. M., Parreira, F. J., \& Shitsuka, R. (2018). Metodologia da pesquisa científica. UFSM. https://repositorio.ufsm.br/bitstream/handle/1/15824/Lic_Computacao_Metodologia-Pesquisa-Cientifica.pdf?sequence=1.

Petter, F. A., Madari, B. E., Silva, M. A. S., Carneiro, M. A. C., Carvalho, M. T., \& Pacheco, L. P. (2012). Soil fertility and upland rice yield after biochar application in the Cerrado. Pesquisa Agropecuária Brasileira, 47 (5), 699-706. https://doi.org/10.1590/S0100-204X2012000500010

Peter, F. A., Lima, L. B., Morales, M. M., Marimon Jr., B. H., \& Morais, L.A. (2016). Biocarvão no Solo: Aspectos agronômicos e Ambientais. VIII SIMBRAS, 73-81. http://www.alice.cnptia.embrapa.br/alice/handle/doc/1055986

Pinto, A. L. (2018). Influência de plantas de cobertura e de biocarvão na estrutura de comunidades microbianas do solo em áreas de mineração de carvão em recuperação (Dissertação de mestrado). Universidade Federal de Santa Catarina, Santa Catarina, Florianópolis, Brasil.

Rebolledo, A. E., Guadalupe, P. L., Moreno, C. H., Collado, J. L., Alves, J. C., \& Barra, J. D. E. (2016). Biocarbón (Biochar) I: Naturaleza, historia, fabricación y uso en el solo. Terra Latinoamericana, 34, 367-382.

Rezende, E. I. P., Ângelo, L. C., Dos Santos, S. S., \& Mangrich, A. S. (2011). Biocarvão (Biochar) e sequestro de carbono. Rev. Virtual Quím., 3 (5), $426-433$. $10.5935 / 1984-6835.20110046$

Rezende, F. A., Dos Santos, V. A. H. F., Maia, C. M. B. F., \& Morales, M. M. (2016). Biochar in substrate composition for production of teak seedlings. Pesq. Agropec. Bras., 51 (9), 1449-1456. https://doi.org/10.1590/S0100-204X2016000900043

Roberts, K. G., Gloy, B. A., Joseph, S., Scott, N. R., \& Lehmann, J. (2009). Life cycle assessment of biochar systems: estimating the energetic, economic and climate change potential. Environ Sci Technol., 44 (2), 827-833. 10.1021/es902266r

Rodrigues, A. F. (2017). O efeito do biocarvão em mudas da Mata Atlântica: uma análise ambiental e socioeconômica (Dissertação de mestrado). Pontifícia Universidade Católica do Rio de Janeiro, Rio de Janeiro, Rio de Janeiro, Brasil. https://www.maxwell.vrac.pucrio.br/Busca_etds.php?strSecao=resultado\&nrSeq=32332@1

Sánchez-Reinoso, A. D., Ávila-Pedraza, E. G., \& Restrepo-Díaz, H. (2020). Use of biochar in agriculture. Acta Biológica Colombiana, 25 (2), $327-338$. https://doi.org/10.15446/abc.v25n2.79466.

Santalla, M., Omil, B., Rodríguez-Soalleiro, R., \& Merino, A. (2011). Effectiveness of wood ash containing charcoal as a fertilizer for a forest plantation in a temperate region. Plant Soil, 346, 63-78. 2011. 10.1007/s11104-011-0794-y

Schenider, B. G. (2015). Biochar de Lodo de Esgoto e sua influência nas propriedades químicas do solo cultivado com milho (Trabalho de Conclusão de Curso). Faculdade de Agronomia e Medicina Veterinária, Universidade de Brasília, Brasília, Brasil.

Schulz, H., Dunst, G., \& Glaser, B. (2013). Positive effects of composted biochar on plant growth and soil fertility. Agronomy for Sustainable Development, 33 (4), 817-827. 10.1007/s13593-013-0150-0

Serrano, J., Peça, J., Silva, J. M., \& Shahidian, S. (2014). Aplicação de fertilizantes: tecnologia, eficiência energética e ambiente. Revista Ciências Agrárias, 37 (3), 270-279. https://doi.org/10.19084/rca.16823

Shabangu, S., Woolf, D., Fisher, E. M., Angenent, L. T., \& Lehmann, J. (2014). Techno-economic assessment of biomass slow pyrolysis into different biochar and methanol concepts. Fuel., 117, 742-748. https://doi.org/10.1016/j.wasman.2021.09.014 
Research, Society and Development, v. 11, n. 2, e55711225999, 2022

Silva, I. C. B., Fernandes, L. A., Colen, F., Sampaio, R. A. (2017). Growth and production of common bean fertilized with biochar. Ciência Rural, 47 (11), 1-8. https://doi.org/10.1590/0103-8478cr20170220

Silva, L. G. (2018). Atividade microbiana do solo, promoção de crescimento e controle da murcha de fusarium em tomateiro influenciados por finos de carvão (Dissertação de mestrado). Universidade Federal de Lavras, Lavras, Minas Gerais, Brasil, 2018. http://repositorio.ufla.br/jspui/handle/1/29414

Silva, M. S. A. (2017). Biochar de casca de pequi como condicionador de solo no desempenho agronômico de feijoeiro (Dissertação de mestrado). Universidade Federal de Minas Gerais, Montes Claros, Minas Gerais, Brasil. http://hdl.handle.net/1843/NCAP-AQBGZZ

Sizmur, T., Quilliam, R., Puga, A. P., Moreno-Jiménez, E., Beesley, L., \& Gomes-Eyles J.L. (2015). Application of biochar for soil remediation. Agricultural and Environmental Applications of Biochar: Advances and Barriers. 295-324.

Solla-Gullon, F., Santalla, M., Rodriguez, R., \& Merino, A. (2006). Nutritional status and growth of a young Pseudotsuga menziesii plantation in a temperate region after application of wood-bark ash. Forest Ecology and Management, 237, 312-321. 10.1016/j.foreco.2006.09.054

Song, X. D., Xue, X. Y., Chen, D. Z., He, P. J., \& Dai, X. H. (2014). Application of biochar from sewage sludge to plant cultivation: Influence of pyrolysis temperature and biochar-to-soil ratio on yield and heavy metal accumulation. Chemosphere, 109, 213-220. 10.1016/j.chemosphere.2014.01.070

Souchie, F. F., Marimon Junior, B. H., Petter, F. A., Madari, B. E., Marimon, B. S., \& Lenza, E. (2011). Carvão pirogênico como condicionante para substrato de mudas de Tachigali vulgaris L.G. Silva \& H.C. Lima. Ciência Florestal, 21 (4), 811-821. http://www.alice.cnptia.embrapa.br/alice/handle/doc/920214

Souza, A. J. (2016). Impacto da biodiversidade bacteriana sob a degradação clorotalonil no solo manejado com biochar (Dissertação de mestrado). Universidade de São Paulo (Escola Superior de Agricultura "Luiz de Queiroz"), Piracicaba, São Paulo, Brasil.

Souza, E. C., Pimenta, A. S., Silva, A. J. F., Braga, R. M., Azevedo, T. K. B., \& Medeiros-Neto, P. N. (2020). Efficiency of $\mathrm{H}_{2} \mathrm{O}_{2}$-treated eucalyptus biochar on the removal of $\mathrm{Cu}(\mathrm{II}), \mathrm{Cd}(\mathrm{II})$ and $\mathrm{Ni}(\mathrm{II})$ from aqueous solution. Revista Brasileira de Ciências Agrárias - Brazilian Journal of Agricultural Sciences, 15(3), 113. https://doi.org/10.5039/agraria.v15i3a6530

Souza, E. C., Pimenta, A. S., Silva, A. J. F., Nascimento, P. F. P., \& Ighalo, J. O. (2021). Oxidized eucalyptus charcoal: a renewable biosorbent for removing heavy metals from aqueous solutions. Biomass Conversion and Biorefinery. https://doi.org/10.1007/s13399-021-01431-y

Souza, G. K. A., Teixeira, W. G., Reis, R. A., Chaves, F. C. M., \& Xavier, J. J. B. N. (2006). Growth of crajiru (Arrabidaea chica Verlot.) on different growing media. Rev. Bras. Pl. Med., 8 (n.esp), 62-65. http://www.alice.cnptia.embrapa.br/alice/handle/doc/680890

Steiner, C., Teixeira, W. G., Lehmann, J., Nehls, T., De Macedo, J. L. V., Blum, W. E. H., \& Zech, W. (2007). Long term effects of manure, charcoal and mineral fertilization on crop production and fertility on a highly weathered Central Amazonian upland soil. Plant Soil, 291, 275-290. 10.1007/s11104-007-9193-

Tan, Z., Lin, C. S., Ji, X., \& Rainey, T. J (2017). Returning biochar to fields: A review. Applied Soil Ecology, 116, 1-11. https://doi.org/10.1016/j.apsoil.2017.03.017

Tenório, F. A. (2017). Cultivo de feijão comum sob aplicação de biocarvão do endocarpo do Ouricuri (Syagrus coronata (Mart.) Becc): atributos químicos e biológicos do solo (Dissertação de mestrado). Universidade Federal de Alagoas, Rio Largo, Alagoas, Brasil. http://www.repositorio.ufal.br/jspui/handle/riufal/5929

Trazzi, P. A., Higa, A. R., Dieckow, J., Mangrich, A. S., \& Higa, R. C. V. (2018). Biocarvão: Realidade e potencial de uso no meio florestal. Ciência Florestal, 28 (2), 875-887. https://doi.org/10.5902/1980509832128

Vendruscolo, E. P. (2015). Qualidade física e química de um solo em recuperação com plantas nativas e introduzidas há 9 anos, após uso de biochar (Dissertação de mestrado). Universidade Federal do Mato Grosso do Sul, Chapadão do Sul, Mato Grosso do Sul, Brasil. https://repositorio.ufms.br/handle/123456789/3115

Woiciechowski, T., Lombardi, K. C., Garcia, F. A. O., \& Gomes, G. S. (2018). Nutrientes e umidade do solo após a incorporação de biocarvão em um plantio de Eucalyptus benthamii Forest. Ciência Santa Maria, 28 (4), 1455-1464. https://doi.org/10.5902/1980509835053

Yuan, J., Xu, R., Qian, W., \& Wang, R. (2011). Comparison of the ameliorating effects on an acidic ultisol between four crop straws and their biochars. Journal of Soils and Sediments, Landsberg, 11 (5), 741-750. https://doi.org/10.1007/s11368-011-0365-0

Zhao, S. X., Ta, N., \& Wang, X. D. (2017). Effect of temperature on the structural and physicochemical properties of biochar with apple tree branches as feedstock material. Energies, 10 (9), 1-15. https://doi.org/10.3390/en10091293 